\title{
Transient Confinement of the Quaternary Tetramethylammonium Tetrafluoroborate Salt in Nylon 6,6 Fibres: Structural Developments for High Performance Properties
}

\author{
Ahmed Dawelbeit and Muhuo Yu* \\ State Key Laboratory for Modification of Chemical Fibers and Polymer Materials, College of Materials Science \\ and Engineering, Donghua University, Shanghai 201620, China; 413004@mail.dhu.edu.cn \\ * Correspondence: yumuhuo@dhu.edu.cn
}

Citation: Dawelbeit, A.; Yu, M. Transient Confinement of the Quaternary Tetramethylammonium Tetrafluoroborate Salt in Nylon 6,6 Fibres: Structural Developments for High Performance Properties. Materials 2021, 14, 2938. https:// doi.org/10.3390/ma14112938

Academic Editor: Jānis Andersons

Received: 24 April 2021

Accepted: 26 May 2021

Published: 29 May 2021

Publisher's Note: MDPI stays neutral with regard to jurisdictional claims in published maps and institutional affiliations.

Copyright: (c) 2021 by the authors. Licensee MDPI, Basel, Switzerland. This article is an open access article distributed under the terms and conditions of the Creative Commons Attribution (CC BY) license (https:/ / creativecommons.org/licenses/by/ $4.0 /)$.
Abstract: A temporary confinement of the quaternary tetramethylammonium tetrafluoroborate $\left(\mathrm{TMA} \mathrm{BF}_{4}\right.$ ) salt among polyamide molecules has been used for the preparation of aliphatic polyamide nylon 6,6 fibres with high-modulus and high-strength properties. In this method, the suppression or the weakening of the hydrogen bonds between the nylon 6,6 segments has been applied during the conventional low-speed melt spinning process. Thereafter, after the complete hot-drawing stage, the quaternary ammonium salt is fully extracted from the drawn $3 \mathrm{wt} . \%$ salt-confined fibres and the nascent fibres are, subsequently, thermally stabilized. The structural developments that are acquired in the confined-nylon 6,6 fibres are ascribed to the developments of the overall fibres' properties due to the confinement process. Surprisingly, unlike the neat nylon 6,6 fibres, the X-ray diffraction (XRD) patterns of the as-spun salt-confined fibres have shown diminishing of the $(110) /(010)$ diffraction plane that obtained pseudohexagonal-like $\beta^{\prime}$ structural phase. Moreover, the $\beta^{\prime}$ pseudohexagonallike to $\alpha$ triclinic phase transitions took-place due to the hot-drawing stage (draw-induced phase transitions). Interestingly, the hot-drawing of the as-spun salt-confined nylon 6,6 fibres achieved the same maximum draw ratio of 5.5 at all of the drawing temperatures of 120,140 and $160{ }^{\circ} \mathrm{C}$. The developments that happened produced the improved values of $43.32 \mathrm{cN} /$ dtex for the tensile-modulus and $6.99 \mathrm{cN} /$ dtex for the tensile-strength of the reverted fibres. The influences of the TMA BF 4 salt on the structural developments of the crystal orientations, on the morphological structures and on the improvements of the tensile properties of the nylon 6,6 fibres have been intensively studied.

Keywords: nylon 6,6 fibres; polyamide fibres; crystal orientation; morphological structural developments; quaternary tetramethylammonium tetrafluoroborate; hydrogen bonds

\section{Introduction}

The well-known routes for obtaining high-moduli and high-strength polymeric fibres are the extensibility-based strengthening of the aliphatic molecules as well as the unfoldable-molecules-based stiffening of the aromatic molecules (the stiff molecules do not fold up into lamellae in the presence of aromatic rings) [1]. The extensibility-based strengthening arose, theoretically, from having high deformability along the molecular chains of the semicrystalline fibres [2]. In this aspect, many attempts had been made to improve the tensile properties of polymeric fibres, as a result of the structural developments along the fibres' axis [3]—such as the flexible ultra-high molecular weight polyethylene [4,5]. However, the aliphatic polyamide nylon 6,6 [6] are the first synthetic fibres that are generally melt spun fibres [7] - which is in contrast to polyethylene, consisting of amide linkages (-NH-CO-) attached directly to two aliphatic groups (alkyl groups) which leads to hydrogen bonded semi-crystalline flexible molecules fibres [8]. On the other hand, the nature of the crystal structure for extruded nylon 6,6 fibres [9] and films [10] is a pseudohexagonal $\beta$ crystal phase structure that develops into a triclinic $\alpha$ crystal phase structure upon the subsequent cooling process [11] or under water treatment [12]. The nylon 6,6 fibres, since 
their discovery, have been very important textile and technical fibres [13]. However, the achieved values of the tensile properties still are far away from the theoretical ones [14].

Naturally, the formation of the high-moduli and high-strength nylon 6,6 fibre is, mainly, dependent on the crystalline structure of the as-spun $\beta$ phases and their development (patently, $\beta$ to $\alpha$ phases transitions). Here, the hydrogen bonds between the nylon 6,6 molecules are, basically, immobile up to the melting temperature, and these hydrogen bonds constitute the main obstacle towards obtaining the abovementioned high draw ratios and high crystal orientations of the nylon 6,6 fibres. (N.B. one must be careful to differentiate between the as-spun pseudohexagonal $\beta$ crystal phase and the Brill temperature pseudohexagonal $\beta$ crystal phase. The former is the crystal structure of the nascent as-just spun fibres (melt extrudate) before the spinline-crystallization and the latter is the structural deformation after the thermal treatment up to the melting point-that causes merging between the intrasheet/interchain $(100)$ and the intersheet $(110) /(010)$ diffraction planes to form a single diffraction at a temperature near $160^{\circ} \mathrm{C}$, i.e., Brill transition [15]. It is to be noted that solution wet spinning only forms fibres that crystallize in triclinic $\alpha$ crystal phase structures [11]). Moreover, in the melt spinning process, nylon 6,6 has fast crystallization kinetics since the formed-yet fibres (the extrudate) tend to crystallize in the spin line in the form of $\alpha$ triclinic crystal phase [16] before the alignment of the molecules! Therefore, to enhance the drawability of the polyamide molecules it is necessary to prevent the crystallization by the suppression or the weakening of the formed hydrogen bonds $[17,18]$ to allow the fibres to be drawn at high draw ratios (plateau deformation), i.e., the highest improvement for the mechanical properties of the fibres will be obtained by the ultimate crystalline orientations [19].

Numerous research methods used to improve the mechanical properties through the structural development of the crystal orientations of nylon 6,6 fibres have been reported, these include spinning (the high-speed melt spinning [20-23], the wet spinning [24], the dryjet wet spinning of the reversible solvent-counter-ions $\left(\mathrm{GaCl}_{3}\right)$ complexation [25-31] and the solution spinning of the reversible superheated water-counter-ions (LiI) shielding [32]) and the drawing (the heat drawing and the annealing [33-37]) methods. It is worth to note here that the montmorillonite clay (MMT) [38-40], the multi-wall carbon nanotube (MWNT) [41,42] and the nanodiamond [43] nanocomposite methods as well as the lithium chloride ( $\mathrm{LiCl})$ [44] and the ferric chloride $\left(\mathrm{FeCl}_{3}\right)$ [45] interactions have, also, been used to modulate the crystal structure of nylon 6,6 materials.

The quaternary tetramethylammonium tetrafluoroborate $\left(\mathrm{TMA} \mathrm{BF}_{4}\right)$ salt is, basically consisting of tetramethylammonium (organic) cations and tetrafluoroborate (inorganic) anions, and has the chemical formula $\left[\left(\mathrm{CH}_{3}\right)_{4} \mathrm{~N}\right]^{+}\left[\mathrm{BF}_{4}\right]^{-}$[46]. Interestingly, its most desirable characteristic is the small sizes (ionic radius) of both the cations and the anions of the TMA BF 4 salt. The size of the TMA cation is $0.283 \mathrm{~nm}$-which is smaller than the smallest ionic radius of any other alkylammonium cations, where the size of the $\mathrm{BF}_{4}$ anion is $0.229 \mathrm{~nm}$ [47]. One may note here that this small size makes TMA $\mathrm{BF}_{4}$ favourable for many applications. It is widely used in electrochemistry for increasing the conductivity of electrodes [48-51] or in the carbon electrodes' voids to enhance the capacitance [52]. Beside their uses in electrochemical applications, they can be confined in supramolecular capsules [53] and deep cavitands [54] as well as intercalate in MMT clay for clay modifications [55]. Additionally, $\mathrm{TMA} \mathrm{BF}_{4}$ is thermally and electrochemically stable and has good mobility. The nanostructure size of the TMA BF 4 is smaller than the hydrogen bond distance between two adjacent molecules [56]. TMA BF 4 is also a water-soluble material with a high-degree of inter- and intra-molecular hydrogen bonding.

In this research work, novel nylon 6,6 fibres are prepared by the temporal reversible salt-confined method using low-speed melt spinning, so as to produce high-strength and high-modulus fibres. The nylon 6,6 resin and $\mathrm{TMA} \mathrm{BF}_{4}$ salt are melt spun by a single-screw melt spinning machine followed by a hot-drawing process (for the as-spun salt-confined fibres) with different drawing ratios and at different drawing temperatures. Then, subsequently, salt-extraction processes followed by immediate thermal stabilization 
processes are applied to the fibres for the reversion of the pristine ones (N.B.: The reversion processes of the fibres are applied when the molecular chains are totally oriented and are fully extended).

\section{Materials and Methods}

\subsection{Materials}

The aliphatic polyamide polymer pellets nylon $6,6 \mathrm{Zytel}^{\circledR} 101 \mathrm{~L}$ - used here-is manufactured by The DuPont Company Ltd., (Wilmington, NC, USA), while, tetramethylammonium tetrafluoroborate electrolyte salt $\left(\mathrm{CH}_{3}\right)_{4} \mathrm{~N}\left(\mathrm{BF}_{4}\right)$ is purchased from The Shanghai ChengJie Chemical Company (Shanghai, China).

\subsection{Fibre Formation}

The spinning and the take-up machines are manufactured by ABE Engineering Company (Tokyo, Japan), while the parallel drawing machine which used for hot-drawing is manufactured by Suzhou Electrical Technology Development Company (Suzhou, China). In the confinement process of the nylon 6,6 fibres-made here-the aliphatic polyamide nylon 6,6 pellets and the $\mathrm{TMA} \mathrm{BF}_{4}$ salt are co-fed into a single screw melt spinning machine (Temtec, Kyoto, Japan) at temperatures in the $295-300{ }^{\circ} \mathrm{C}$ range. The salt weight to nylon 6,6 weight ratios are $0,1,2,3$ and $4 \%$. The extrudate is spun out through a spinneret of 36 holes with a diameter of $0.3 \mathrm{~mm}$ for each hole. However, the TMA BF 4 salt-confined nylon 6,6 fibres (thereafter is referred to as salt-confined nylon 6,6 fibres (the abbreviation "IS" in the figures' captions and the tables' entries, also stands for TMA BF 4 salt) have been wound up at a winding speed of $306 \mathrm{~m} / \mathrm{min}$ for neat and salt-confined nylon 6,6 fibres. Moreover, all of the as-spun fibres are individually subjected to hot-drawing processes at temperatures of 120,140 and $160^{\circ} \mathrm{C}$. The results of the melt spinning and the hot-drawing processes of the salt-confined nylon 6,6 fibres revealed - experimentally-that, the additional amount of the $\mathrm{TMA} \mathrm{BF}_{4}$ contents influence the maximum achievable drawing ratios of the salt-confined fibres-which is very low for salt contents of less than $3 \%$. In this piece of work, out of the total of the nylon 6,6 salt-confined fibres which are prepared, only those that are confined with $3 \mathrm{wt} . \%$ TMA BF4 and hot drawn at the temperatures of 120, 140 and $160^{\circ} \mathrm{C}$ are chosen to test whether the salt-confined at low-speed melt spinning method is worked well for improving the mechanical properties of the nylon 6,6 fibres, or not-concentred studies has been made on theses fibres because they have shown the greatest drawing ratio (of 5.5) and, consequently, the greatest extensibility.

The salt-extraction process has been carried out by immersing the drawn salt-confined nylon 6,6 fibres into a $10 \%$ pentahydrate sodium thiosulphate $\left(\mathrm{Na}_{2} \mathrm{~S}_{2} \mathrm{O}_{3} \cdot 5 \mathrm{H}_{2} \mathrm{O}\right)$ solution at room temperature for about $12 \mathrm{~h}$. The treated fibres are, subsequently, washed with a deionized water for another hour and, finally, the resulting fibres are dried in an oven at $50{ }^{\circ} \mathrm{C}$ for one hour. Thereafter, the salt-free regenerated fibres-referred to here as the regenerated fibres-have been subjected to a thermal stabilization treatment in a heating tube at $190^{\circ} \mathrm{C}$ under tension in an inert nitrogen gas atmosphere, as illustrated in Scheme S3 below. The resulted thermally stabilized fibres are referred to as the stabilized fibres.

\subsection{Characterization Techniques}

\subsubsection{Fourier Transforms Infra-Red Spectroscopy (FTIR)}

A Fourier-transform Infra-red (FTIR) spectrometer is used to characterize the chemical composition and to differentiate between the crystalline structure phases of the nylon 6,6 fibres and their development due to the deformations processes. The crystal structure developments of the salt-confined nylon 6,6 fibre have been investigated using a Nicolet 6700 FTIR-ATR instrument (Thermo Fisher Scientific Inc., Waltham, MA, USA). The scanning number for each sample is 16 and $0.482 \mathrm{~cm}^{-1}$ for the data spacing used. The data fitting and the analyses are processed by the OMNIC (Thermo Fisher Scientific Inc., Waltham, MA, USA) and the Origin Lab (8.5, Origin Lab corporation Northampton, MA, USA) softwares. 


\subsubsection{X-ray Diffraction (XRD)}

The crystal structures of the neat and the salt-confined nylon 6,6 fibres are investigated using an X-ray polycrystal diffractometer (XRD) - D/max-2550 PC, manufactured by Rigaku (Tokyo, Japan).

\section{Crystal Size}

The apparent crystallite size $(A C S)$ of the neat and the salt-confined nylon 6,6 fibres have been calculated by the Scherrer equation (Equation (1)):

$$
A C S=\frac{K \lambda}{\beta \cos \theta}
$$

where: $\theta$ is the Bragg diffraction angle of the equatorial plane, $\lambda(=1.541 \AA)$ is the $\mathrm{X}$-ray wave length and $K$ is a constant whose value is dependent on the crystallite shape.

\section{Crystal Orientation}

The orientation parameters $\left\langle\cos ^{2} \varnothing_{h k l}\right\rangle$ are calculated from the mean-square cosine of the angle $\left(\varnothing_{h k 1}\right)$ and are defined by the equation (Equation (2)):

$$
\left\langle\cos ^{2} \varnothing_{h k l}\right\rangle=\frac{\int_{0}^{\frac{\pi}{2}} I\left(\varnothing_{h k l}\right) \cos ^{2} \varnothing_{h k l} \sin \varnothing_{h k l} d \varnothing_{h k l}}{\int_{0}^{\frac{\pi}{2}} I\left(\varnothing_{h k l}\right) \sin \varnothing_{h k l} d \varnothing_{h k l}}
$$

where $\varnothing_{h k l}$ is the azimuthal angle measured from the equatorial planes and $I\left(\varnothing_{h k l}\right)$ is the fully corrected intensity distribution. The values of the orientation parameter $\left\langle\cos ^{2} \varnothing_{h k l}\right\rangle$ of the molecules have the values of unity for the parallel oriented molecules, zero for perpendicularly oriented molecules and one third for randomly oriented molecules to the fibre axis.

The Hermans's orientation function $\left(f_{c}\right)$ describes the degree of orientation via the equation (Equation (3)):

$$
f_{c}=\frac{\left\langle\cos ^{2} \varnothing_{h k l}\right\rangle-1}{2}
$$

where the angle $\left(\varnothing_{h k l}\right)$ is the angle between the polymer chains and the fibres axis.

The Hermans's orientation function $\left(f_{c}\right)$ can be seen to have the values of unity when the molecular chain of the fibres is paralleled with the fibre axis, -0.5 when the molecular chain is perpendicular to the fibre axis and zero when the molecular chain is totally unoriented.

\section{The Crystal Perfection Index (CPI)}

The crystal perfection index (CPI) for the neat and the salt-confined nylon 6,6 fibres is defined by the equation (Equation (4)):

$$
C P I \%=100 \times\left(\frac{\left(d_{100} / d_{010}\right)-1}{0.189}\right)
$$

where $d_{100}$ and $d_{010}$ are the interplanar lattice spacings for the (100) and the (010) diffraction planes, respectively, and the factor 0.189 is the corresponding value for the well-crystallized sample (the ideal crystal structure).

\subsubsection{Nuclear Magnetic Resonance (NMR)}

The solid state ${ }^{13} \mathrm{C}-\mathrm{NMR}$ measurements of the as-spun neat and salt-confined nylon 6,6 fibres have been carried out on an AVANCE 400 NMR spectrometer (Bruker, Switzerland). The fibres are cut into short pieces, prior to the investigation, and filled into a cylindrical ceramic rotor for ${ }^{13} \mathrm{C} C \mathrm{C} / \mathrm{MAS}$ spectra, The NMR spectrometer was operated 
at $100 \mathrm{MHz}$ for the samples and spun at spin rate of $5 \mathrm{kHz}$. The glycine upfield peak $(176.03 \mathrm{ppm})$ relative to tetramethylsilane (TMS) $\left[\left(\mathrm{CH}_{3}\right)_{4} \mathrm{Si}\right]$ is used for the calibration.

\subsubsection{Scanning Electron Microscope (SEM)}

The morphological structures of the neat and the salt-confined nylon 6,6 fibres are obtained using a Field Scanning Electron Microscope (SEM) - Hitachi SU8010 and S-4800supplied by Hitachi (Tokyo, Japan).

\subsubsection{Mechanical Properties}

The mechanical properties of the neat and the salt-confined nylon 6,6 fibres were determined by a XL-2 tensile strength testing machine for fibre bundles. The machine is supplied by Shanghai New Fibre Instrument Limited Company (Shanghai, China). A pneumatic device is used for clamping the fibres during the tensile measurement, with the effective gauge length set of $50 \mathrm{~mm}$. The mechanical properties of the reverted fibres are characterized by an XL-1 Tensile Strength Testing Machine also supplied by Shanghai New Fibre Instrument Limited Company, Shanghai-with clamping of $10 \mathrm{~mm}$ for each single fibre. A pneumatic device id also used for clamping the fibres during the tensile property measurements.

\section{Results and Discussions}

\subsection{Structural Development of the Salt-Confined Nylon 6,6 Fibres \\ 3.1.1. Fourier Transform Infra-Red Spectroscopy (FTIR)}

FTIR spectroscopy is used to investigate the chemical and the crystal structure of the quaternary ammonium salt, the as-spun and drawn neat nylon 6,6 fibres and the as-spun and drawn salt-confined nylon 6,6 fibres with different contents. The bands assignments of the FTIR spectra in the ranges of $4000-600 \mathrm{~cm}^{-1}, 1500-1100 \mathrm{~cm}^{-1}$ and $1100-800 \mathrm{~cm}^{-1}$ for the as-spun neat and for the as-spun salt-confined nylon 6,6 fibres are illustrated in Figure 1a-c. The FTIR results show that all of the peaks of the neat nylon 6,6 fibres also occur in the saltconfined nylon 6,6 fibres [57]. The FTIR spectra for both of the neat and the salt-confined nylon 6,6 fibres show peaks at 936 and $906 \mathrm{~cm}^{-1}$ which are attributed to the crystalline phase structure for both types of the fibres. The FTIR spectra for the neat fibres show a peak at $1640 \mathrm{~cm}^{-1}$ attributed to the fibres' amorphous phase structure. As for the salt-confined fibres, the FTIR spectra show for them peaks in the range $1639.26-1639.70 \mathrm{~cm}^{-1}$. However, the FTIR peak at $1180 \mathrm{~cm}^{-1}$ for the neat fibres does not change its position due to either the salt-confinement or due to the hot drawing processes-this peak is used as a reference band for the nylon 6,6 fibres. This observation of assigning the $1180 \mathrm{~cm}^{-1}$ band as a reference band for the nylon 6,6 fibres was also mentioned by Vasanthan and Salem [58] for the FTIR band assignment of the heat-treated nylon 6,6 fibres as can be deduced from Figure 2a.

It is worth noting that, contrary to Vasanthan et al. [58,59], the above FTIR results found in this research study do not show any crystalline phase peaks at $924 \mathrm{~cm}^{-1}$ for any of the types of the nylon 6,6 fibres considered.

On the other hand, the FTIR spectrum bands of the TMA BF 4 salt are, mainly classified based on the tetragonal symmetry of the arrangement of the methylene groups in the $\left[\left(\mathrm{CH}_{3}\right)_{4} \mathrm{~N}\right]$ cation and the disordered $\left[\mathrm{BF}_{4}\right]$ anion which located with the one $\mathrm{B}-\mathrm{F}$ bond lying on the fourfold (tetragonal) axis and the other three F-ions making a triangle with a disordered distribution (trigonal axis) [49,60]. The FTIR results show absorption bands at $949,1292,1410,1492$ and $3052 \mathrm{~cm}^{-1}$ that are attributed to the $\left[\left(\mathrm{CH}_{3}\right)_{4} \mathrm{~N}\right]$ cations and, also, bands at 769, 1034 and $1049 \mathrm{~cm}^{-1}$ for the $\left[\mathrm{BF}_{4}\right]$ anions [61,62]. The band at $3052 \mathrm{~cm}^{-1}$ is interpreted to be due to the $\mathrm{N}-\mathrm{CH}_{3}$ stretching mode and the symmetric and antisymmetric $\mathrm{C}-\mathrm{H}$ bending of the methyl terminal belonging to the cations. The band at about $949 \mathrm{~cm}^{-1}$ is found to be compatible with the breathing of the NC4 skeleton, although that band at $1049 \mathrm{~cm}^{-1}$ can be assigned to the stretch vibration modes of the $\left[\mathrm{BF}_{4}\right]$ anions groups too. 

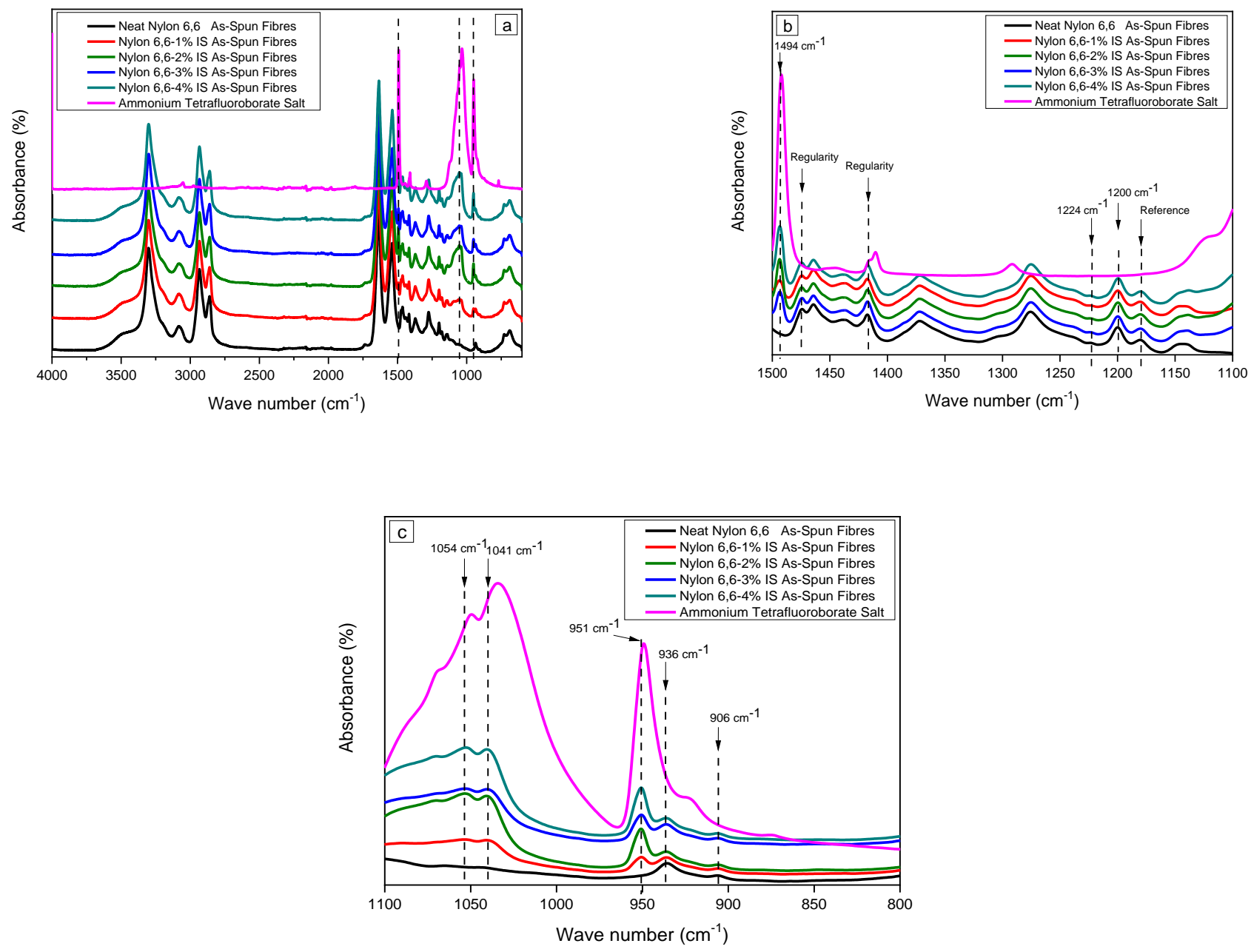

Figure 1. The FTIR spectra of the as-spun neat and salt-confined nylon 6,6 fibres in the band regions of (a) $4000-600 \mathrm{~cm}^{-1}$, (b) $1500-1100 \mathrm{~cm}^{-1}$ and (c) $1100-800 \mathrm{~cm}^{-1}$.
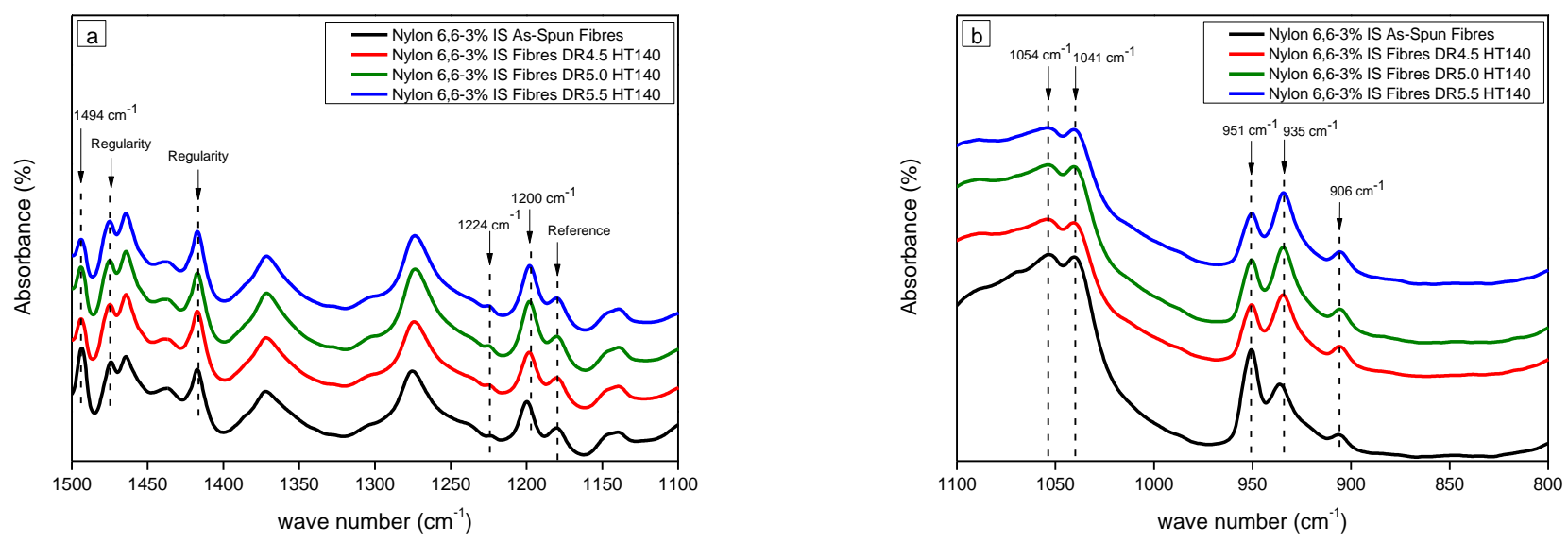

Figure 2. The FTIR spectra of the as-spun and drawn salt-confined nylon 6,6 fibres at the drawing temperature of $140{ }^{\circ} \mathrm{C}$ at the band regions of (a) $1500-1100 \mathrm{~cm}^{-1}$ and (b) $1100-800 \mathrm{~cm}^{-1}$.

Moreover, the FTIR spectra showed four new absorption bands for the $3 \mathrm{wt} . \%$ as-spun salt-confined nylon 6,6 fibres at the wavenumbers $1494 \mathrm{~cm}^{-1}, 1054 \mathrm{~cm}^{-1}, 1041 \mathrm{~cm}^{-1}$ and $951 \mathrm{~cm}^{-1}$. These bands, which can clearly be observed in Figure $2 \mathrm{~b}$, are attributed to the TMA $\mathrm{BF}_{4}$-which showed a red shift for the stretching vibrations [63] away from that for the pure $\mathrm{TMA} \mathrm{BF}_{4}$ salt. This result is believed to occur as a result of the hydrogen bonding 
interactions between the cations and the anions of the TMA BF 4 salt and the carbonyl (donors) and the amine (acceptors) segments of the amide groups that took-place among the nylon 6,6 molecules. Despite the hydrogen bonds interactions between the polyamide segment are fixed up to the melting temperature and also did not change with molten salt $[64,65]$, the as-spun salt-confined fibres show that the full width at half maximum (FWHM) of the carbonyl peak of the solid state ${ }^{13} \mathrm{C}-\mathrm{NMR}$ is wider than that of the neat nylon 6,6 fibres-which is an evidence for the interruption of the hydrogen bonds through the salt-confinement process-see Figure 3. Furthermore, the absorption band at $936 \mathrm{~cm}^{-1}$ of the as-spun salt-confined nylon 6,6 fibres showed a slight shift to the smaller values of $934 \mathrm{~cm}^{-1}$ and $935 \mathrm{~cm}^{-1}$ due to the hot-drawing stage for the drawing ratios of 4.5, 5.0 and 5.5 at the drawing temperatures of 120,140 and $160{ }^{\circ} \mathrm{C}$ (see Supplementary Material Figures S1-S3).

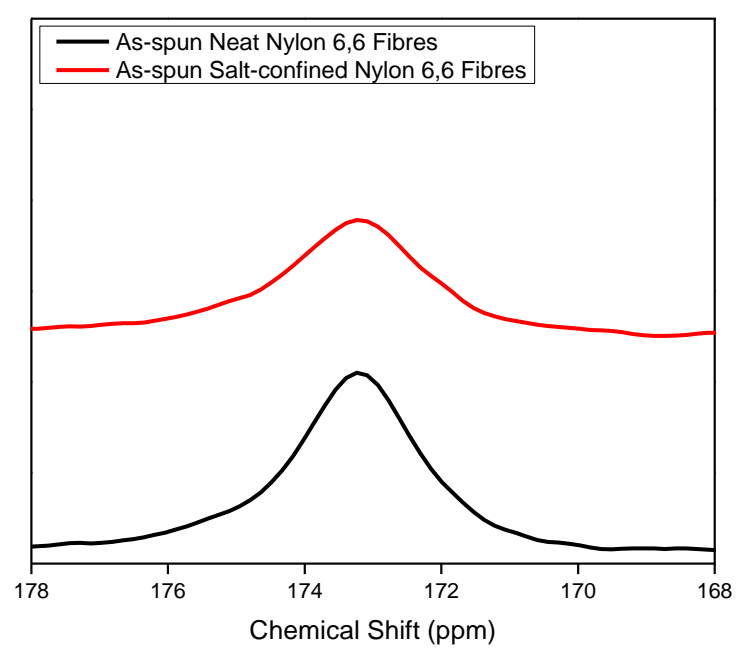

Figure 3. Solid state ${ }^{13} \mathrm{C}-\mathrm{NMR}$ spectra of the as-spun neat and the as-spun salt-confined nylon 6,6 fibres.

\subsubsection{X-ray Diffraction (XRD)}

Generally, in the formation of the semicrystalline nylon 6,6 fibres, the relationships between the undrawn fibre structure, the drawing conditions, the structures and properties of the drawn fibres are considered to be essential features to improve the drawing process for achieving high tensile strengths and high tensile moduli for the nylon 6,6 fibres. Here, it is known that, the drawing conditions, the structures and properties of the resulting drawn fibres (triclinic $\alpha$ crystal phase structure) are strongly governed by the quality and the characteristics of the original-undrawn as-spun fibres (pseudohexagonal $\beta$ crystal phase structure). The molecular extensibility and the crystallites alignment along the fibre axis of the amide molecules (molecular orientations) are regularly concomitant with the changes in the phase structure ( $\beta$ to $\alpha$ phases transitions) and in the other morphological structure features (spherulites and fibrillar structures).

\section{The Crystal Structure}

The XRD diffraction patterns of the as-spun neat and the salt-confined nylon 6,6 fibres are shown in Figures 4 and 5 and the values of the crystal parameters are tabulated in Table 1 . The results shown here indicate that the hydrogen bonding among the molecular segments of the as-spun nylon 6,6 molecules has been suppressed or interrupted by the confinement of the $\mathrm{TMA} \mathrm{BF}_{4}$ inorganic salt. 


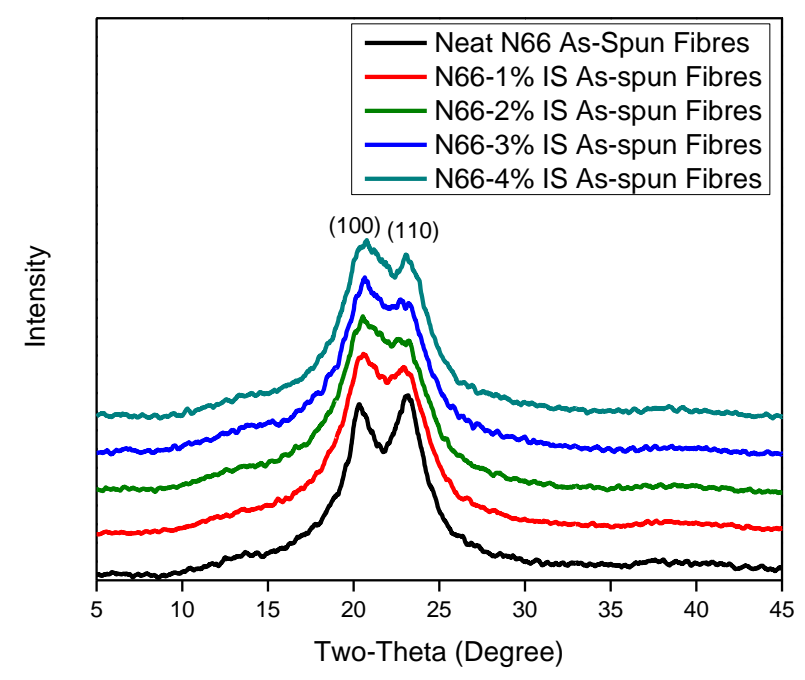

Figure 4. XRD pattern of neat and different salt-confined nylon 6,6 fibres.

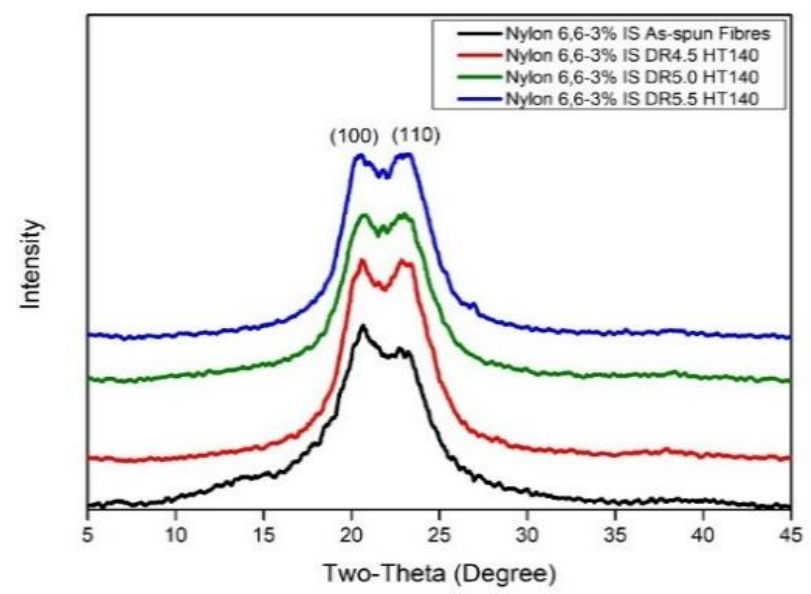

Figure 5. XRD pattern of 3\% salt-confined as-spun and drawn nylon 6,6 fibres at drawing temperature of $140{ }^{\circ} \mathrm{C}$.

Table 1. Crystallographic properties of the as-spun neat and salt-confined nylon 6,6 fibres.

\begin{tabular}{|c|c|c|c|c|c|c|c|c|c|}
\hline \multirow[t]{2}{*}{ Sample } & \multirow{2}{*}{$\begin{array}{c}\text { Crystallinity } \\
(\%)\end{array}$} & \multicolumn{2}{|c|}{$\begin{array}{c}\text { Interplanar Space } \\
\text { (d-Spacing), } \AA\end{array}$} & \multirow{2}{*}{$\begin{array}{l}\text { Crystal } \\
\text { Perfection, } \\
\text { CPI (\%) }\end{array}$} & \multicolumn{2}{|c|}{$\begin{array}{c}\text { Apparent Crystal } \\
\text { Size, ACS (̊̊) }\end{array}$} & \multirow{2}{*}{$\cos ^{2} \varnothing_{h k l}$} & \multirow{2}{*}{$\begin{array}{c}\text { Degree of } \\
\text { Orientation } \\
\quad\left(f_{c}\right)\end{array}$} & \multirow{2}{*}{$\begin{array}{c}\text { Orientation } \\
\text { Angle } \\
\text { (Degree) }\end{array}$} \\
\hline & & (100) & (010) & & (100) & (010) & & & \\
\hline $\begin{array}{l}\text { Neat nylon 6,6, } \\
\text { as-spun fibres }\end{array}$ & 38.24 & 4.3671 & 3.8541 & 70.426 & 70 & 56 & 0.238 & -0.144 & 60.84 \\
\hline $\begin{array}{l}\text { Nylon } 6,6-1 \% \text { IS } \\
\text { as-spun fibre }\end{array}$ & 58.60 & 4.3247 & 3.8473 & 65.655 & 28 & 33 & 0.625 & 0.438 & 37.76 \\
\hline $\begin{array}{c}\text { Nylon } 6,6-2 \% \text { IS } \\
\text { as-spun fibre }\end{array}$ & 64.76 & 4.3344 & 3.8418 & 67.842 & 29 & 27 & 0.653 & 0.480 & 36.10 \\
\hline $\begin{array}{l}\text { Nylon } 6,6-3 \% \text { IS } \\
\text { as-spun fibre }\end{array}$ & 63.33 & 4.3184 & 3.8419 & 65.623 & 31 & 27 & 0.460 & 0.191 & 47.27 \\
\hline $\begin{array}{l}\text { Nylon 6,6-4\% IS } \\
\text { as-spun fibre }\end{array}$ & 59.23 & 4.3195 & 3.8048 & 71.575 & 26 & 37 & 0.618 & 0.428 & 38.16 \\
\hline
\end{tabular}

It is known that the crystallization of the just spun molecules (as-spun fibres) adopts a staggered arrangement of the $\beta$ crystal phase structure yielding a pseudohexagonal unit cell. The structural developments at the formation of the as-spun nylon 6,6 fibres yield a stable $\alpha$ crystal phase structure. The resulting $\alpha$ crystal phase exhibits progressive arrangements of the amide molecules with a triclinic unit cell structure $[66,67]$. The TMA 
$\mathrm{BF}_{4}$ salt has a monoclinic unit cell [68] and the highest diffraction peak occurred at twotheta of $21.5^{\circ}$ with the interplanar spacing of $4.126 \AA$-as shown in Figure S4. While, the results of the TMA BF 4 salt confinement among the molecular chains of the nylon 6,6 fibres show an interruption of the hydrogen bonds between the carbonyl and the amine segments of the amide functional group-which turn in inhibiting the melt crystallization of the salt-confined nylon 6,6 fibres. This is an indication that weakening took place among the hydrogen bonds (i.e., the effectiveness of the hydrogen bonds has been reduced) in the saltconfined fibres. Surprisingly, at the drawing process, these results lead to a maximum draw ratio of 5.5 for the $3 \mathrm{wt} . \%$ salt-confined nylon 6,6 fibre for all of the drawing temperatures of 120,140 and $160{ }^{\circ} \mathrm{C}$. On the other hand, the maximum draw ratio of the neat nylon 6,6 fibres varies from 5.0 at the drawing temperatures of 120 and $140{ }^{\circ} \mathrm{C}$ to 5.5 at the drawing temperature of $160^{\circ} \mathrm{C}$.

Interestingly, the salt-confined nylon 6,6 fibres reveal that, the $\beta^{\prime}$-to- $\alpha$ phase transitions took-place during the hot-drawing stage (stress-induced phase transitions) to develop a triclinic $\alpha$ crystal phase structure-as shown in Figure 5, Figure S5 and Figure S6. This finding is contrary to the results described by Ramesh et al. [11] and Vergelati et al. [12].

The interplanar spacing (d-spacing) of the (100) and (110)/(010) diffraction planes takes values of 4.3671 and $3.8541 \AA$, respectively, for the as-spun neat fibres and the spacing values of 4.3763 and $3.8854 \AA$ respectively, for the drawn neat fibres at drawing temperatures of $140{ }^{\circ} \mathrm{C}$. In the confined fibres, however, the XRD pattern of the as-spun $3 \%$ salt-confined fibres rises two diffraction peaks for the (100) and for the $(110) /(010)$ diffraction planes at $20.550^{\circ}$ and $23.132^{\circ}$ with the interplanar spacing of 4.3184 and $3.8419 \AA$, respectively. Furthermore, the drawn salt-confined fibres at drawing ratio of 5.5 and a drawing temperature of $140^{\circ} \mathrm{C}$ exhibits two diffraction peaks at $20.298^{\circ}$ and $23.110^{\circ}$ with the interplanar spacings of 4.3713 and $3.8455 \AA$, respectively.

Moreover, the salt confinement among the molecular chains of the nylon 6,6 fibres led to the variation in the interplanar spacing values for the as-spun neat and salt-confined fibres that is reflected in developing small crystal sizes-as shown in Table 2. It is to be noted here that the position of the XRD diffraction peak for the (100) plane is increased when the drawing temperature is raised from 140 to $160^{\circ} \mathrm{C}$ at the drawing ratio of 5.5-this can be attributed to the structural deformations at the Brill transition temperature $\left(T_{B}\right)$ of the nylon 6,6 [69].

Table 2. Crystallographic properties of the as-spun and drawn salt-confined nylon 6,6 fibres.

\begin{tabular}{|c|c|c|c|c|c|c|c|c|c|}
\hline \multirow[t]{2}{*}{ Samples } & \multirow{2}{*}{$\begin{array}{c}\text { Crystallinity } \\
(\%)\end{array}$} & \multicolumn{2}{|c|}{$\begin{array}{c}\text { Interplanar Space } \\
\text { (d-Spacing), } \AA\end{array}$} & \multirow{2}{*}{$\begin{array}{l}\text { Crystal } \\
\text { Perfection, } \\
\text { CPI (\%) }\end{array}$} & \multicolumn{2}{|c|}{$\begin{array}{c}\text { Apparent Crystal } \\
\text { Size, ACS (A) }\end{array}$} & \multirow{2}{*}{$\cos ^{2} \varnothing_{h k l}$} & \multirow{2}{*}{$\begin{array}{l}\text { Degree of } \\
\text { Orientation } \\
\qquad\left(f_{c}\right)\end{array}$} & \multirow{2}{*}{$\begin{array}{c}\text { Orientation } \\
\text { Angle } \\
\text { (Degree) }\end{array}$} \\
\hline & & $(100)$ & $(010)$ & & $(100)$ & (010) & & & \\
\hline $\begin{array}{l}\text { Nylon } 6,6-3 \% \text { IS } \\
\text { as-spun fibre }\end{array}$ & 63.33 & 4.3184 & 3.8419 & 65.623 & 31 & 27 & 0.460 & 0.191 & 47.27 \\
\hline $\begin{array}{c}\text { Nylon } 6,6-3 \% \text { IS DR } \\
4.5 \text { HT120 }\end{array}$ & 71.24 & 4.3243 & 3.8142 & 70.760 & 31 & 29 & 0.741 & 0.612 & 30.57 \\
\hline $\begin{array}{c}\text { Nylon 6,6-3\% IS DR } \\
5.0 \text { HT120 }\end{array}$ & 69.17 & 4.3297 & 3.8028 & 73.31 & 32 & 28 & 0.868 & 0.803 & 21.28 \\
\hline $\begin{array}{c}\text { Nylon 6,6-3\% IS DR } \\
5.5 \text { HT120 }\end{array}$ & 72.58 & 4.3489 & 3.8266 & 72.218 & 35 & 29 & 0.760 & 0.640 & 29.34 \\
\hline $\begin{array}{c}\text { Nylon } 6,6-3 \% \text { IS DR } \\
4.5 \text { HT140 }\end{array}$ & 58.36 & 4.3520 & 3.8549 & 68.23 & 47 & 33 & 0.843 & 0.764 & 23.35 \\
\hline $\begin{array}{c}\text { Nylon 6,6-3\% IS DR } \\
5.0 \text { HT140 }\end{array}$ & 50.09 & 4.3444 & 3.8627 & 65.98 & 44 & 31 & 0.790 & 0.686 & 27.24 \\
\hline $\begin{array}{c}\text { Nylon } 6,6-3 \% \text { IS DR } \\
5.5 \text { HT140 }\end{array}$ & 58.02 & 4.3713 & 3.8455 & 72.35 & 44 & 30 & 0.928 & 0.892 & 15.55 \\
\hline $\begin{array}{c}\text { Nylon } 6,6-3 \% \text { IS DR } \\
4.5 \text { HT160 }\end{array}$ & 50.39 & 4.3405 & 3.8537 & 66.84 & 41 & 32 & 0.825 & 0.738 & 24.70 \\
\hline $\begin{array}{c}\text { Nylon 6,6-3\% IS DR } \\
5.0 \text { HT160 }\end{array}$ & 52.64 & 4.3460 & 3.8527 & 67.75 & 42 & 29 & 0.935 & 0.903 & 14.76 \\
\hline $\begin{array}{c}\text { Nylon } 6,6-3 \% \text { IS DR } \\
5.5 \text { HT160 }\end{array}$ & 54.86 & 4.3516 & 3.8577 & 67.74 & 49 & 27 & 0.886 & 0.829 & 19.72 \\
\hline
\end{tabular}




\section{Crystal Orientation}

Typical drawing of the semicrystalline nylon 6,6 fibres occurs by pulling out the polyamide molecules from the folded lamellar crystal into well oriented crystals, without losses (breaking) in the taut molecules and without losses in the covalent bonded chain (backbone molecule). The as-spun neat and the as-spun 3\% salt-confined nylon 6,6 fibres exhibit unoriented molecular orientations of the polyamide molecules. However, the molecular orientations of the neat and the salt-confined nylon 6,6 fibres greatly increase with the increase of the drawing ratios from 1.0 to 5.5. These results revealed that the salt confinement of the ammonium salt among the nylon 6,6 molecules have strongly affected the existed hydrogen bonding at the melt spinning process and have inhibited the crystallization of the molten extrudate of the nascent nylon 6,6 fibres. Indeed, the full width at half maximum (FWHM) has, clearly, showed random crystal orientations of the as-spun confined fibres in comparison with the neat ones-as seen in Figure 6. The FWHM of the azimuthal angle decreases due to the increase of the deformation when both types of the as-spun nylon 6,6 fibres are hot-drawn. Moreover, the effect of changing the drawing temperature on the Herman's orientation function of the as-spun and drawn neat fibres and the as-spun and drawn salt-confined nylon 6,6 fibres takes different values at the same fixed drawing ratio. Furthermore, the Herman's orientation function has exhibited the highest value at the drawing ratio 5.5 at the drawing temperature of $140{ }^{\circ} \mathrm{C}$.
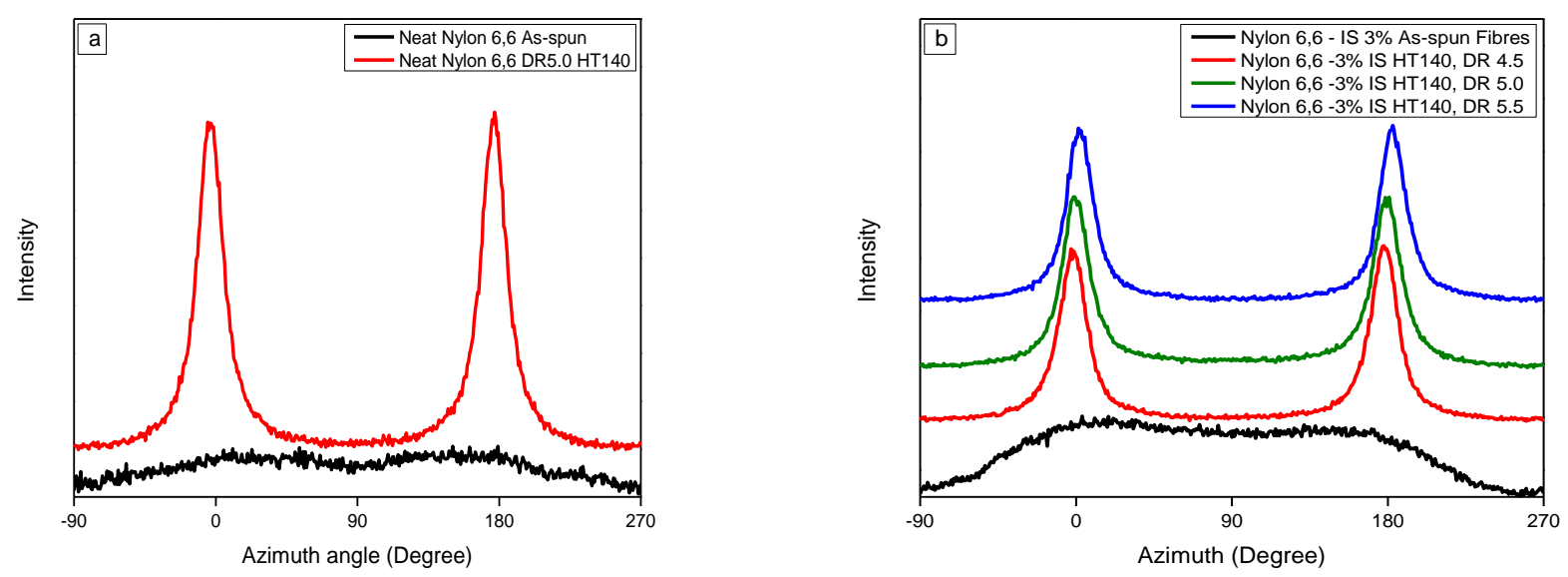

Figure 6. Azimuthal angle of as-spun and drawn neat (a) and salt-confined (b) nylon 6,6 fibres at different drawing ratio at drawing temperature of $140{ }^{\circ} \mathrm{C}$.

These fibres have, also, obtained the smallest value for the orientation angle (the angle between the polymeric molecular chains and the fibre axis) - as shown in Figure 7. Surprisingly, increasing the drawing temperature has no effect on the extensibility (draw ratio).

\section{Crystallinity}

The as-spun neat nylon 6,6 fibres exhibit two peaks for the interchain/interasheet (100) and the intersheet (110)/(010) diffraction planes, but, in contrast to the neat fibres, the as-spun salt-confined nylon 6,6 fibres show for the (100) peak relatively high intensity compared to the intensity of the intersheet $(110) /(010)$ peak due to the interaction of the $\mathrm{TMA} \mathrm{BF}_{4}$ salt with the amide group via the hydrogen bonds. This observation confirms the breaking of the hydrogen bonds-as shown in Figure 8. The results, here, give values of the crystallinity of the as-spun salt-confined fibres higher than that of the as-spun neat fibres-which are melt-spun at the same melting temperatures and at the same spinning speed conditions. The increase of the crystallinity of the as-spun salt-confined fibres is believed to be attributed to the effect of the crystal size of the nascent fibres. Moreover, the small crystal size of the salt-confined crystals can be ascribed to the influences of the nanoscale size of the $\mathrm{TMA} \mathrm{BF}_{4}$ salt—which have the ability to infiltrate inside the lamella 
structure of the spherulites. However, when the drawing temperature is increased to $140{ }^{\circ} \mathrm{C}$ the value of the crystallinity for the salt-confined fibres has exhibited a slight reduction for the high drawing ratio of 5.5- see Table 2. Here, the crystallinity values for the drawn fibres had been reduced to values lower than that for the as-spun salt-confined ones-which is attributed to morphological structurals' changes due to the partial breaking of the amide (original) hydrogen bonding and forming strong (new) hydrogen bonds between the TMA $\mathrm{BF}_{4}$ salt and the amide groups. In addition, the intermediate structures (mesophases) tend to transform into amorphous phases not crystalline ones [70].

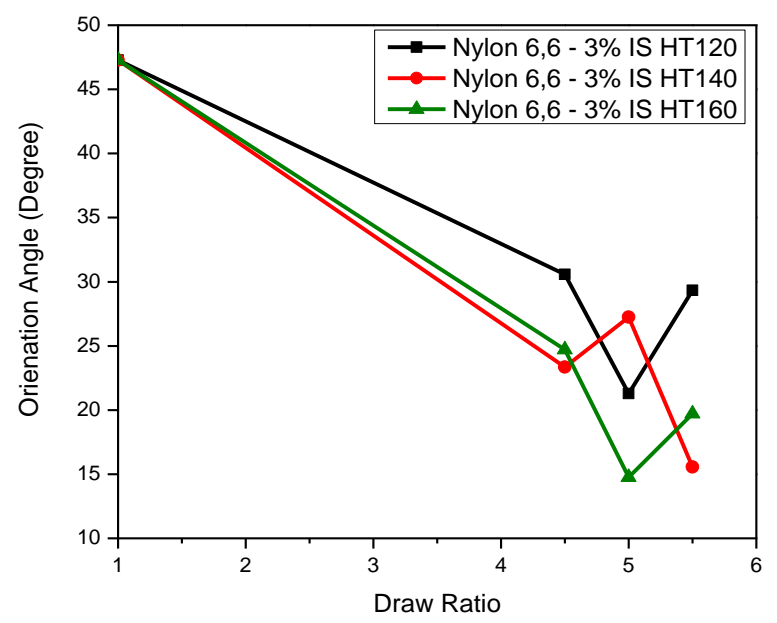

Figure 7. The orientation angle of the salt-confined nylon 6,6 fibres versus the drawing ratios of 1.0, 4.5, 5.0 and 5.5 at different drawing temperatures.

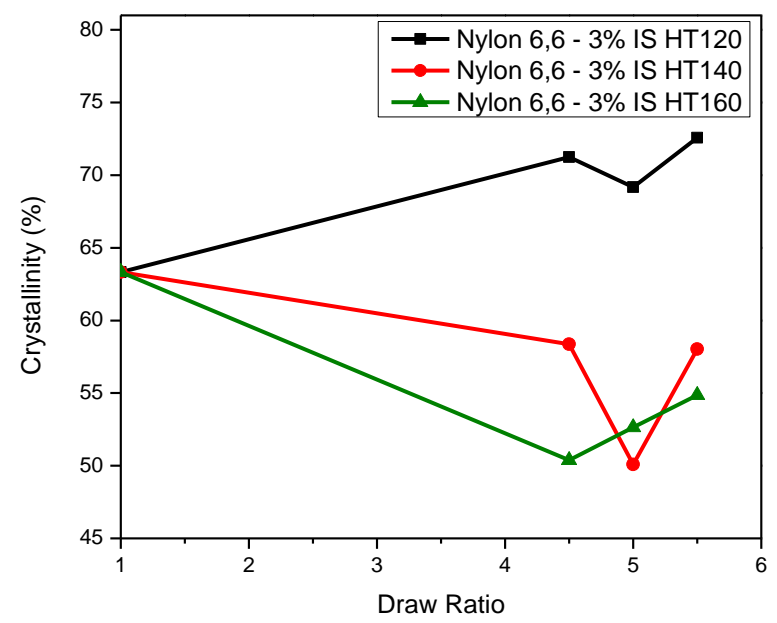

Figure 8. The crystallinity of the salt-mediated nylon 6,6 fibres versus the drawing ratios of 1.0, 4.5, 5.0 and 5.5 at different drawing.

The Apparent Crystal Size (ACS) and The Crystal Perfection Index (CPI)

It worth noting that, due to the salt confinement of the $\mathrm{TMA} \mathrm{BF}_{4}$ salt, the as-spun salt-confined fibres exhibited crystal sizes (ACS) smaller than that of the as-spun neat fibres-see Figure 9. The crystal size of the as-spun 3\% wt salt-confined fibres had been found to be smaller than half the crystal size of the as-spun neat nylon 6,6 fibres in both the hydrogen bonded (interasheet/interchain) and the van der Waal (intersheet) directions. A possible explanation is that the salt confinement lead to hindering the large crystal growth. This is similar to the nanotube net-work structure of the MWNT-modified nylon 6,6 nanocomposites [41]. However, when applying the hot drawing process, the ACS of the neat drawn fibres at the (100) and (110/010) planes concurrently decreases with the increase of the drawing ratio as shown in Table S1. On the contrary, it has been observed 
that the converse takes place for the salt-confined nylon 6,6 fibres i.e., its crystal size increases with increasing the drawing ratio-see Figure S7. This result revealed that the crystals sizes variations of the $(110 / 010)$ planes during the drawing processes at different drawing temperatures-for the salt-confined fibres-are much smaller than the crystal size of the (100) plane-where the hydrogen bonding takes-place and the crystal growth is fast. However, the $\mathrm{ACS}_{100}$ show significant increase, at the same drawing ratio 5.5, with the increase of the drawing temperature. Obviously, here, the temperature has more effect than the strain. This observation is in agreement with the data reported by Hsiao et al. [69].

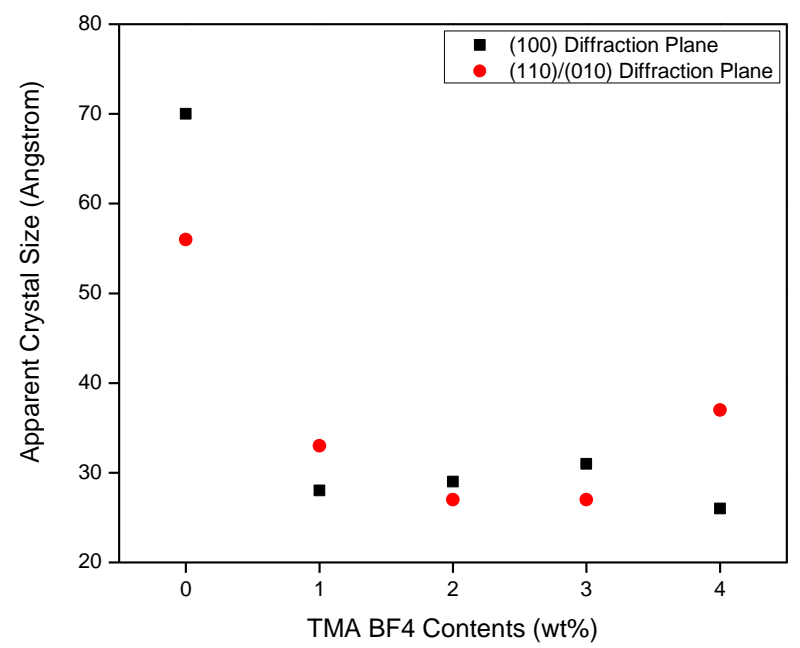

Figure 9. Apparent crystal size of the as-spun salt-confined nylon 6,6 fibres.

On the other hand, the as-spun $3 \%$ salt-confined fibres have shown a crystal perfection index (CPI) of lower value than that for the neat nylon 6,6 fibres. This observation may be attributed to the interaction of the TMA BF 4 salt and the nylon 6,6 among the polyamide molecules which led to the variations in the interplanar spacings (Bragg's spacings) as mentioned above. Moreover, the drawn salt-confined nylon 6,6 fibres have shown considerable improvements in the values of the CPI during the drawing process for all of the drawing ratios and for all of the drawing temperatures. The values of the CPI of the as-spun and drawn 3\% salt-confined nylon 6,6 fibres are plotted in Figure 10, below.

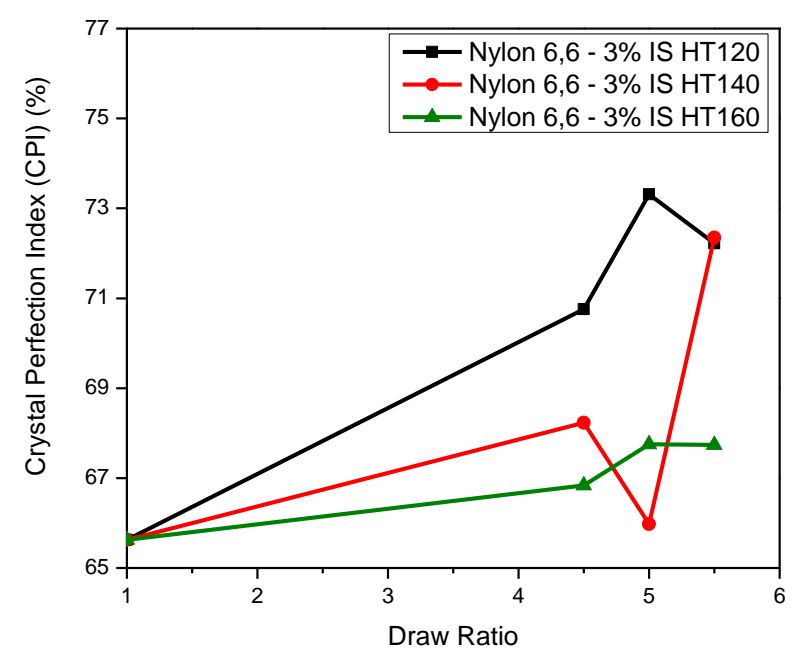

Figure 10. The CPI of the salt-confined nylon 6,6 fibres versus the drawing ratio at different drawing temperatures. 


\subsubsection{Scanning Electron Microscopy (SEM)}

The morphological structures of the surfaces and the cross-sectional areas of the as-spun and drawn salt-confined nylon 6,6 fibres are observed by means of the SEM technique. The SEM micrographs obviously show the axialite or hedrite morphological structure (structure visualized as two hexagonally shaped placed spine to spine) on the surface of the as-spun salt-confined fibres-which eventually develops into spherulites structures [59,71]. However, when the fibres are drawn, these spherulites will turn into the developing of the fibrillar structure. These fibrillar structures have appeared as parallel streaks throughout the surfaces of the fibres as shown in Figure 11. This behaviour has, similarly, been observed during the drawing process of the semicrystalline polyethylene and polypropylene polymers [59]. Besides the molecular orientations and the hydrogen bonds, the microfibrillar morphology determines the mechanical properties of the nylon 6,6 fibres, as well [72]. Moreover, the SEM micrograph, also, has illustrated the TMA BF particles on the surfaces of the fibres. Nevertheless, the cross-sectional views have shown some void structures for both of the as-spun and the drawn fibres. The cross-sectional areas of the drawn salt-confined fibres have shown a pleated-sheet structures as a result of the improvements of the spherical structures due to the hot drawing processes.
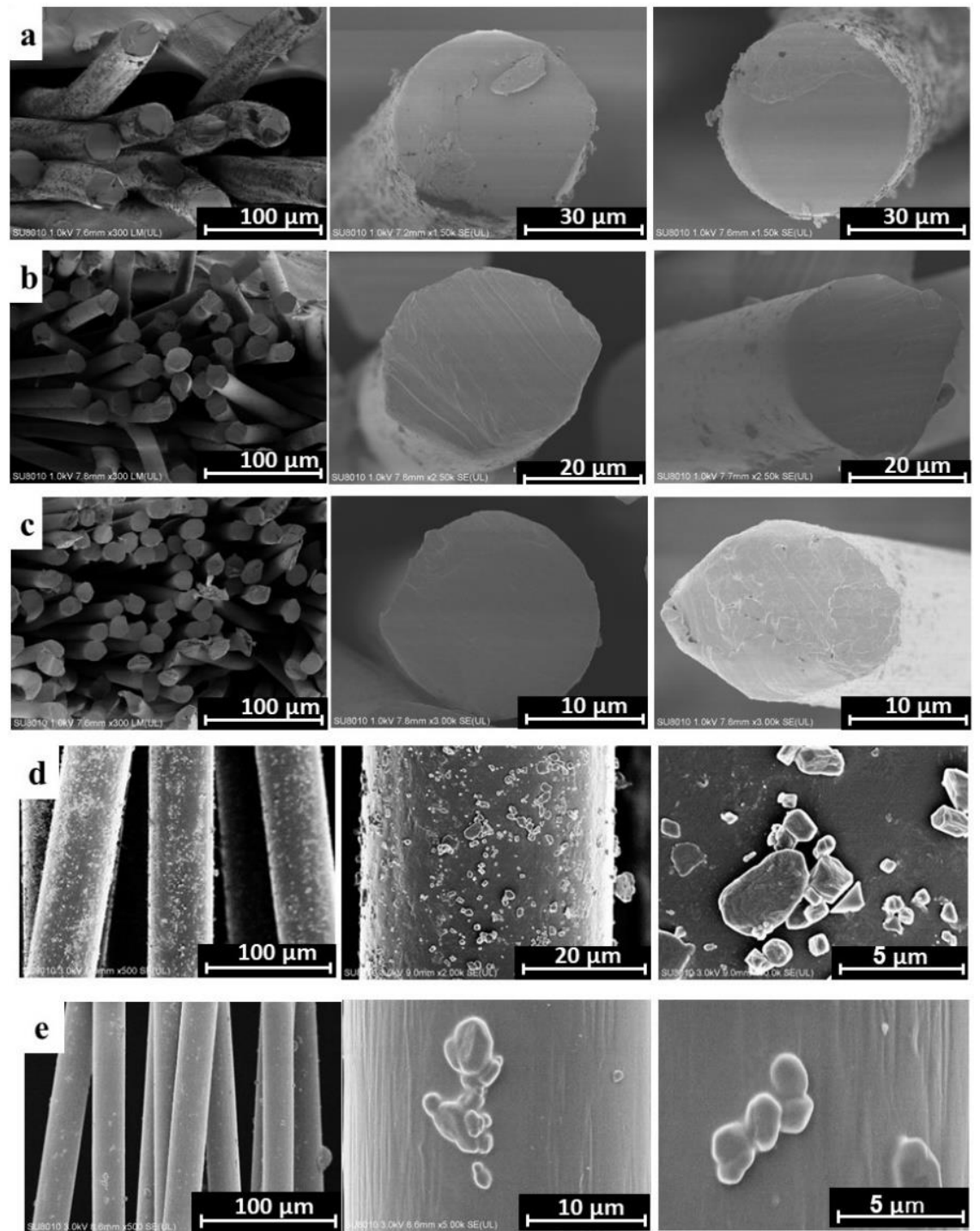

Figure 11. Cont. 


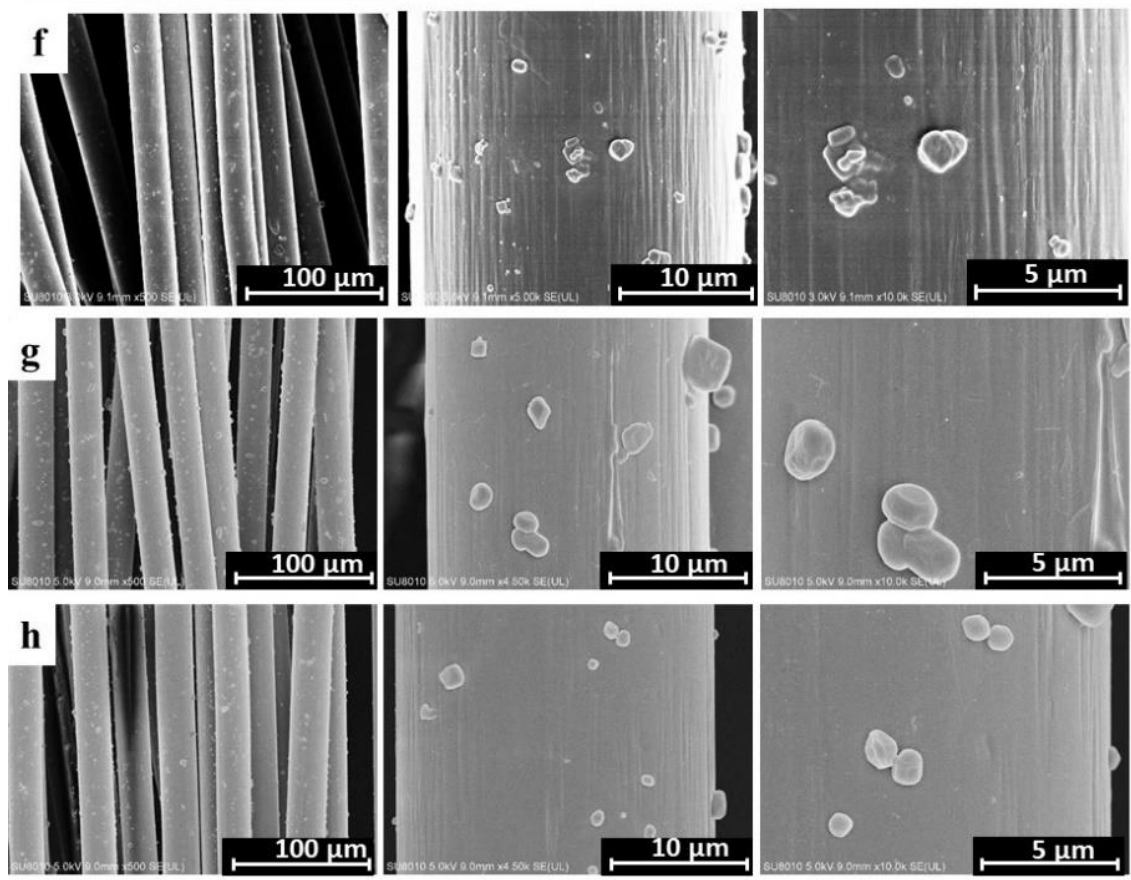

Figure 11. Scanning electron microscopy micrographs of the salt-confined nylon 6,6 fibres. The morphological cross-section structures of the 3\% salt-confined nylon 6,6 (a) as-spun fibres, (b) drawn fibres-DR $4.5 \mathrm{HT} 120{ }^{\circ} \mathrm{C}$ and (c) drawn fibres-DR $5.5 \mathrm{HT} 120{ }^{\circ} \mathrm{C}$. The morphological surfaces structures of the $3 \%$ salt-confined nylon 6,6 (d) as-spun fibres, (e) drawn fibres-DR $4.5 \mathrm{HT} 120^{\circ} \mathrm{C}$, (f) drawn fibres-DR $5.5 \mathrm{HT} 120^{\circ} \mathrm{C}$, (g) drawn fibres-DR $5.5 \mathrm{HT} 140{ }^{\circ} \mathrm{C}$ and (h) drawn fibres-DR 5.5 $\mathrm{HT} 160{ }^{\circ} \mathrm{C}$.

\subsection{Mechanical Properties}

Tentative secession of the hydrogen bonds by means of temporary confinement processes have been used for the preparation of high-modulus and high-strength nylon 6,6 fibres (the high-modulus and the high-strength fibres means the high-performance aliphatic nylon 6,6 fibres). The tensile mechanical properties of the neat and the salt-confined nylon 6,6 fibre are tabulated in Table 3. The results have revealed that, both of the initial moduli and the tensile strengths of the salt-confined nylon 6,6 fibres increase with increasing of the draw ratio-as shown in Table 3 and Figure S8. The tensile moduli values for all of the salt-confined fibres are higher than that for the neat nylon 6,6 fibres at all of the drawing ratios and at all of the drawing temperatures. However, at the drawing temperatures of 120 and $140{ }^{\circ} \mathrm{C}$, the values of the tensile strength for the salt-confined fibres at their maximum drawing ratio (of 5.5) are higher than that for the neat fibres at their maximum drawing ratio (of 5.0). On the other hand, the drawn salt-confined fibres at the drawing temperature $160{ }^{\circ} \mathrm{C}$ and its maximum drawing ratio of 5.5 have shown a slight reduction in the tensile strength value as shown in Figure 12-this can be ascribed to the structural deformations at the Brill transition temperature $\left(T_{B}\right)$ of nylon 6,6 [15]. Moreover, the values of the elongations for all the salt-confined fibres are lower than that values for the neat nylon 6,6 fibres for all of the drawing ratios and at all the drawing temperatures- as a result of the crystal orientation development of the nylon 6,6 molecules. 
Table 3. Mechanical Properties of the Neat and Salt-confined Nylon 6,6 Fibres.

\begin{tabular}{|c|c|c|c|c|c|c|c|c|}
\hline \multirow[b]{2}{*}{$\begin{array}{c}\text { Drawing } \\
\text { Temperature } \\
\left({ }^{\circ} \mathrm{C}\right)\end{array}$} & \multicolumn{4}{|c|}{ Neat Nylon 6,6 Fibres } & \multicolumn{4}{|c|}{ Salt-Confined Nylon 6,6 Fibres } \\
\hline & $\begin{array}{l}\text { Draw } \\
\text { Ratio }\end{array}$ & $\begin{array}{l}\text { Tensile } \\
\text { Modulus } \\
\text { (cN/dtex) }\end{array}$ & $\begin{array}{c}\text { Tensile } \\
\text { Strength } \\
\text { (cN/dtex) }\end{array}$ & $\begin{array}{c}\text { Elongation } \\
(\%)\end{array}$ & $\begin{array}{l}\text { Draw } \\
\text { Ratio }\end{array}$ & $\begin{array}{c}\text { Tensile } \\
\text { Modulus } \\
\text { (cN/dtex) }\end{array}$ & $\begin{array}{c}\text { Tensile } \\
\text { Strength } \\
\text { (cN/dtex) }\end{array}$ & $\begin{array}{c}\text { Elongation } \\
(\%)\end{array}$ \\
\hline 120 & 4.0 & 13.3 & 2.9 & 70.9 & 4.5 & 19.9 & 3.1 & 15.6 \\
\hline 120 & 4.5 & 13.7 & 3.1 & 67.5 & 5.0 & 26.5 & 3.7 & 14.0 \\
\hline 120 & 5.0 & 23.3 & 4.1 & 29.6 & 5.5 & 32.8 & 5.0 & 15.1 \\
\hline 140 & 4.0 & 13.2 & 3.1 & 78.8 & 4.5 & 20.8 & 2.8 & 13.6 \\
\hline 140 & 4.5 & 16.9 & 3.3 & 47.0 & 5.0 & 31.8 & 4.1 & 12.8 \\
\hline 140 & 5.0 & 21.8 & 3.9 & 33.7 & 5.5 & 35.8 & 4.2 & 11.6 \\
\hline 160 & 4.5 & 16.5 & 3.7 & 67.7 & 4.5 & 27.3 & 3.1 & 11.1 \\
\hline 160 & 5.0 & 20.8 & 4.0 & 41.4 & 5.0 & 31.0 & 3.7 & 11.9 \\
\hline 160 & 5.5 & 26.3 & 4.7 & 30.7 & 5.5 & 33.4 & 4.5 & 13.5 \\
\hline
\end{tabular}

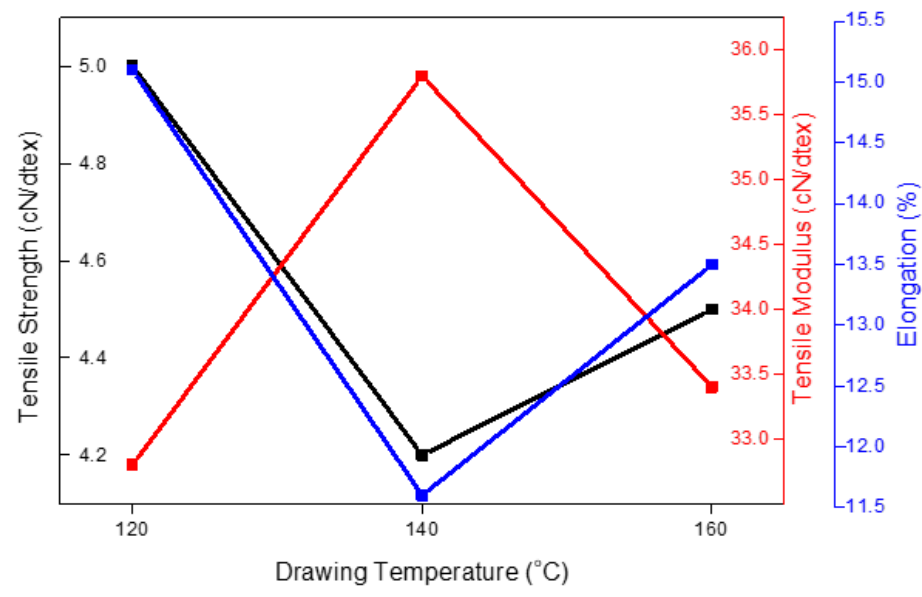

Figure 12. Mechanical properties of the drawn 3\% salt-confined nylon 6,6 fibres at a drawing ratio of 5.5 and drawing temperature of 120,140 and $160^{\circ} \mathrm{C}$.

\subsection{The Extraction of the Confined $\mathrm{TMA} \mathrm{BF}_{4}$ Salt and the Thermal Stabilization Processes}

The reversion process has been made after studying the structural and the mechanical properties of the TMA BF 4 salt-confined nylon 6,6 fibres by the FTIR, SEM, the XRD techniques and mechanical properties.

The FTIR of the salt-confined, regenerated and stabilized nylon 6,6 fibres, as shown in Figure 13a-c, showed the removal of the confined salt from the 3\% salt-confined nylon 6,6 fibres-which was drawn at the maximum obtainable drawing ratio of 5.5 and at drawing temperatures of 120,140 and $160^{\circ} \mathrm{C}$. However, the FTIR spectra show a slight red shift for all of the reverted fibres (an increase in energy). The decrease in the wavelength of the peaks' positions of the reverted fibres, emphasizes the hydrogen bond re-formation between the amide donors and acceptors sides.

The XRD patterns have shown that, the peaks' heights for the diffraction peaks of the regenerated and the stabilized fibres for the (110/010) plane are increased (higher than the peak height of the (100) plane) due to the extraction of the $\mathrm{TMA} \mathrm{BF}_{4}$ salt and the stabilization of the regenerated fibres. Moreover, the peaks positions of the (100) and the (110) planes are shifted towards higher values. Besides the peaks shifting (positions' changes), these results of the XRD testing experiments on the reverted fibres show, also, changes in the peaks widths'. It is known that, the $(110 / 010)$ peak corresponds to the direction of the hydrogen bonding interchain/interasheet. Thus, the reforming of the hydrogen bonding took place among the neighbouring of the extended molecules for the fibres reverted from the drawn $3 \mathrm{wt} . \%$ salt-confined nylon 6,6 fibres drawn at the drawing ratio of 5.5 at drawing temperatures of 120,140 and $160{ }^{\circ} \mathrm{C}$ - see Figure 14. Therefore, 
the crystallinity of the reverted fibres tends to increase due to the crystallization of the well oriented molecules in the amorphous region which engaged in contributing to the crystallinity. The crystal size of the (100) plane of the reverted fibres has exhibited small values-smaller than that values for neat drawn nylon 6,6 fibres $\left(\mathrm{ACS}_{100}=51 \AA\right.$ ). On the other hand, the crystal perfection index (CPI) of the regenerated fibres has shown values higher than the corresponding values for the drawn salt-confined fibres at all of the drawing temperatures of 120,140 and $160^{\circ} \mathrm{C}$. The crystal orientations of the reverted fibres have, also, shown significant improvements due to the reversion processes. The XRD results are tabulated in Table S2. Scheme 1 illustrates the variations of the orientation factor through all of the salt-confined fibres formation and their reversion to the pure nylon 6,6 fibres.
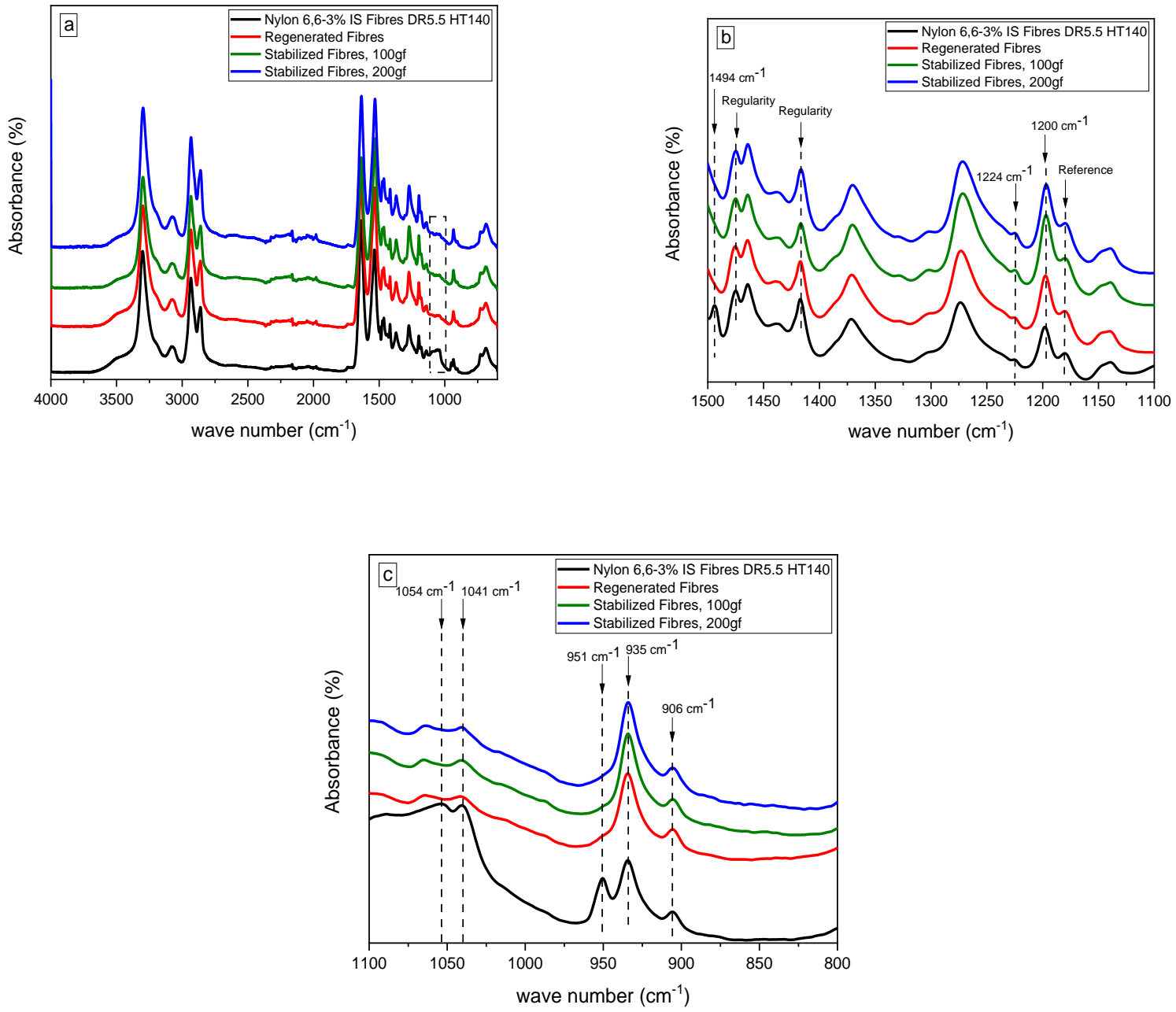

Figure 13. The FTIR spectrum of the salt-confined (drawn at, maximum, 5.5 draw ratio and at drawing temperature of $140^{\circ} \mathrm{C}$ ) and reverted nylon 6,6 fibres at the band regions of (a) $4000-600 \mathrm{~cm}^{-1}$, (b) $1500-1100 \mathrm{~cm}^{-1}$ and (c) $1100-800 \mathrm{~cm}^{-1}$.

The SEM micrographs illustrate the morphological structures of the surfaces and cross-sectional areas of the reverted nylon 6,6 fibres. The morphological structures of the regenerated fibres achieved voids structures on their surfaces and their cross-sections. The reverted fibres have shown smooth surfaces-as shown in Figure 15 for the regenerated and the stabilized nylon 6,6 fibres (the regeneration have been done for the $3 \%$ salt-confined nylon 6,6 fibres drawn at drawing ratio of 5.5 and drawing temperature of $\left.140{ }^{\circ} \mathrm{C}\right)$. However, the cross-sectional areas for the stabilized fibres that are regenerated from the $3 \mathrm{wt} . \%$ saltconfined nylon 6,6 fibres drawn at temperature of $120{ }^{\circ} \mathrm{C}$ and a draw ratio of 5.5 have shown folded lamellar structure. 


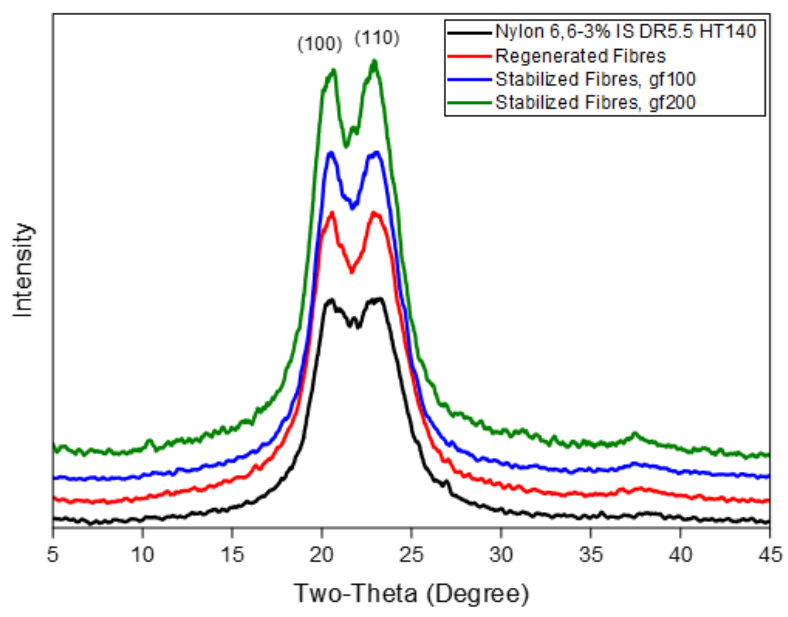

Figure 14. XRD pattern of salt-confined (drawn at, maximum, 5.5 draw ratio and at drawing temperature of $140^{\circ} \mathrm{C}$ ) and reverted nylon 6,6 fibres.

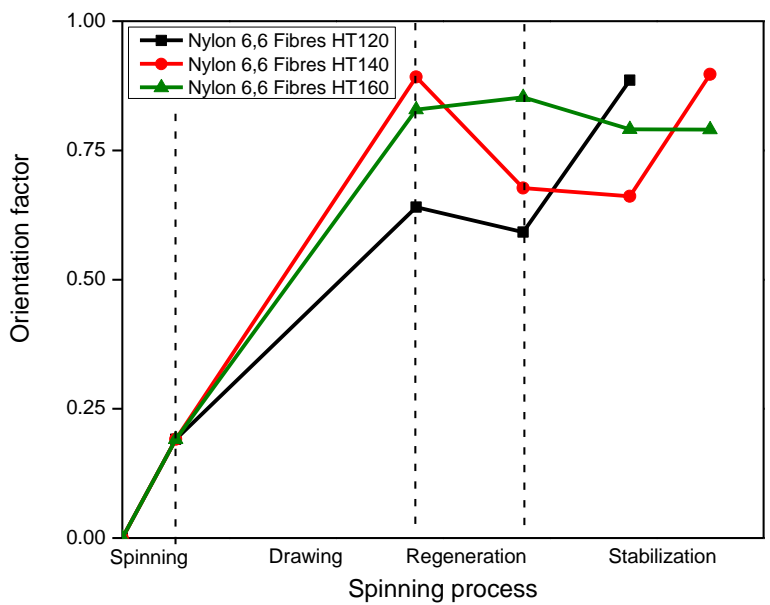

Scheme 1. Orientation changes in the formation of the nylon 6,6 fibres.
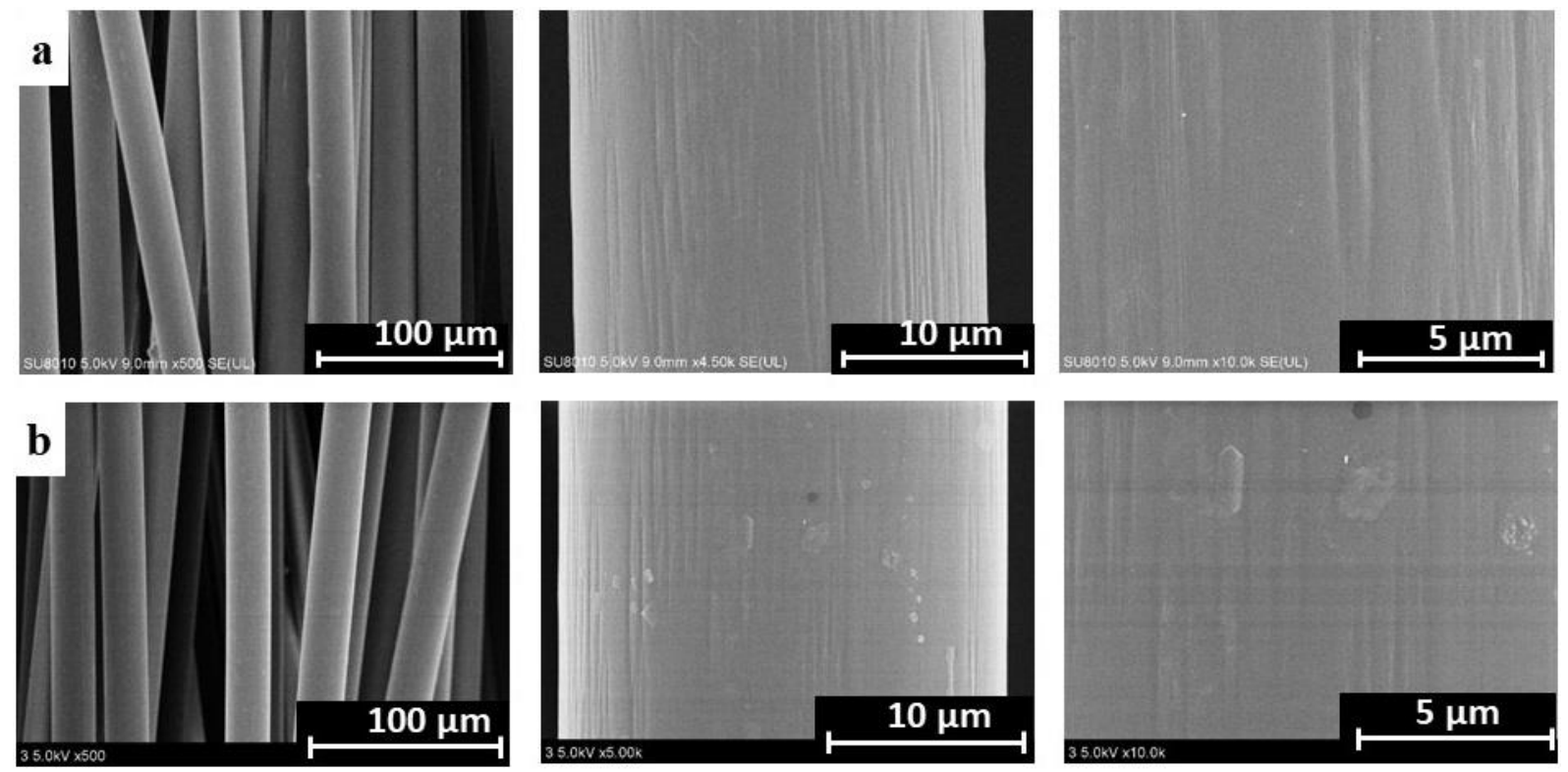

Figure 15. SEM micrograph of (a) the regenerated and (b) the stabilized reverted nylon 6,6 fibres. 
The development of the crystal structure of the melt-spun salt-confined nylon 6,6 fibres is reflected in the improvements of the mechanical properties of the three types of the developed nylon 6,6 fibres (the salt-confined, the regenerated and the thermally stabilized fibres) - as tabulated in Tables 3 and 4 . The results have shown tensile modulus $43.32 \mathrm{cN} / \mathrm{dtex}$ and tensile strength of $6.99 \mathrm{cN} /$ dtex for the reverted fibres.

Table 4. Mechanical Properties of Salt-confined and Reverted Nylon 6,6 Fibres.

\begin{tabular}{|c|c|c|c|c|c|}
\hline Fibre Type * & $\begin{array}{c}\text { Drawing } \\
\text { Temperature }\left({ }^{\circ} \mathrm{C}\right)\end{array}$ & $\begin{array}{c}\text { Tension } \\
\text { (Gram Force) }\end{array}$ & $\begin{array}{l}\text { Tensile Modulus } \\
\text { (cN/dtex) }\end{array}$ & $\begin{array}{c}\text { Tensile Strength } \\
\text { (cN/dtex) }\end{array}$ & $\begin{array}{c}\text { Elongation } \\
(\%)\end{array}$ \\
\hline Regenerated Nylon 6,6 Fibres -1\# & RT & - & 35.62 & 6.31 & 26.57 \\
\hline Stabilized Nylon 6,6 Fibres 1-1 & 190 & $98 \mathrm{cN}$ & 39.94 & 6.81 & 26.07 \\
\hline Stabilized Nylon 6,6 Fibres 1-2 & 190 & $196 \mathrm{cN}$ & 43.32 & 6.99 & 25.06 \\
\hline Regenerated Nylon 6,6 Fibres -2\# & RT & - & 39.81 & 6.48 & 31.70 \\
\hline Stabilized Nylon 6,6 Fibres 2-1 & 190 & $98 \mathrm{cN}$ & 33.44 & 6.55 & 29.23 \\
\hline Stabilized Nylon 6,6 Fibres 2-2 & 190 & $196 \mathrm{cN}$ & 35.96 & 6.94 & 29.20 \\
\hline
\end{tabular}

* Samples 1\# and 2\# are the reversion fibres from the salt-confined nylon 6,6 fibres drawn at 5.5 and at temperatures of 140 and $160{ }^{\circ} \mathrm{C}$, respectively.

Furthermore, the appearance of the salt-confined and the reverted fibres has reflected silver colour-which is known for the melt spinning nylon 6,6 fibres. This silver colour implies the existence of voids inside the resulting fibres [73]. However, an additional SEM analysis using high magnifications have been carried out to investigate the voids formations. The SEM results have, obviously, confirmed that, the morphological structures of the salt-confined and the reverted nylon 6,6 fibres have some voids and cracks structures on their surfaces as shown in Figure 16, below. This formation of the voids structures can be thought about to be the main obstacle towards achieving great improvements in the mechanical properties of the resulting fibres-despite the fact that the achieved values of the tensile strength of the fibres in the above mention reversible $\mathrm{TMA} \mathrm{BF}_{4}$ salt confinement method are higher than their corresponding values for the neat nylon 6,6 fibres.
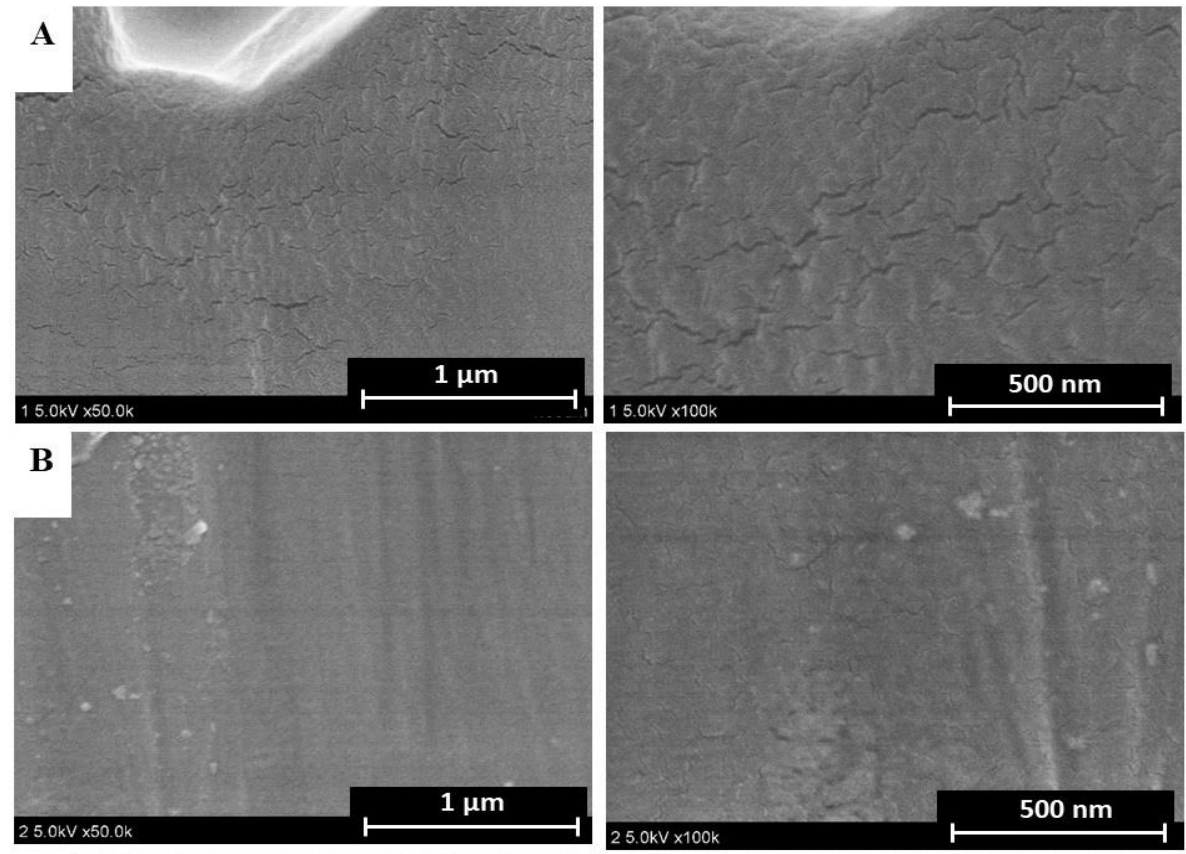

Figure 16. Cont. 

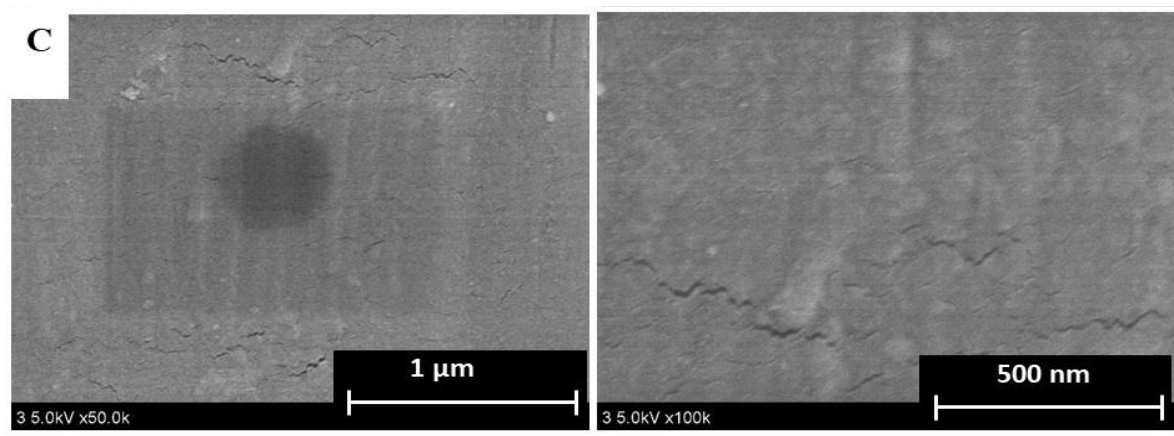

Figure 16. SEM micrographs of the (A) drawn salt-confined nylon 6,6 DR $5.5 \mathrm{HT} 140{ }^{\circ} \mathrm{C}$, (B) regenerated and (C) stabilized nylon 6,6 fibres.

\section{Conclusions}

The application of the reversible method of confinement by quaternary tetramethylammonium tetrafluoroborate $\left(\mathrm{TMA} \mathrm{BF}_{4}\right)$ salt that has been applied among the polyamide molecules of the nylon 6,6 fibres to inhibit (or to weaken) the hydrogen bond formation during the melt spinning process has shown great success. The XRD patterns obtained pseudohexagonal-like $\beta^{\prime}$ structural phase for the $(110) /(010)$ diffraction plane of the asspun salt-confined fibres that have been hot-drawn to orient the molecules along the fibres' axis draw-induced phase transitions (i.e., $\beta^{\prime}$-to- $\alpha$ phase transitions took-place during the hot-drawing stage). This leads to the formation of relatively high-strength and high-modulus fibres. The salt-confined nylon 6,6 fibres achieved ultimate molecular orientations of 5.5 at all of the (used) drawing temperatures and also, exhibited crystal size (ACS) smaller than that of the neat fibres under the same conditions which have been developed during the drawing process. Moreover, the structural developments lead to the improvements of the crystal orientation, the morphological structures as well as the mechanical properties. Interestingly, increasing the drawing temperature is found to have no effect on the molecular chain extensibility (draw ratio). This observation suggests that the ammonium salt confinement took place in the amorphous phase. The silver-coloured appearance of the salt-confined and the reverted nylon 6,6 fibres is an evidence of the formation of voids structures inside these fibres. Despite of the formation of these voids, the mechanical properties of the reverted fibres are improved. These improvements are reflected in the achievements of the reverted fibres of an improved tensile modulus of $43.32 \mathrm{cN} /$ dtex and an improved tensile strength of $6.99 \mathrm{cN} / \mathrm{dtex}$ (these values can be more improved if a way is found to prevent voids formations inside the fibres). Thus, it can be concluded that the application of the reversible salt confinement method to the nylon 6,6 fibres in the melt spinning process leads to the preparation of high-modulus and high-strength polyamide fibres. Moreover, the extraction of the ammonium salt provides a desirable way to achieve a commercially beneficial fibres' formation process.

Supplementary Materials: The following are available online at https:/ / www.mdpi.com/article/

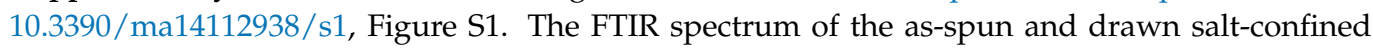
nylon 6,6 fibres at the drawing temperature of $120{ }^{\circ} \mathrm{C}$ at the band regions of (a) $4000-600 \mathrm{~cm}^{-1}$, (b) $1500-1100 \mathrm{~cm}^{-1}$ and (c) $1100-800 \mathrm{~cm}^{-1}$, Figure S2. The FTIR spectrum of the as-spun and drawn salt-confined nylon 6,6 fibres at the drawing temperature of $140{ }^{\circ} \mathrm{C}$ at the band regions of (a) $4000-600 \mathrm{~cm}^{-1}$, (b) $1500-1100 \mathrm{~cm}^{-1}$ and (c) $1100-800 \mathrm{~cm}^{-1}$, Figure S3. The FTIR spectrum of the as-spun and drawn salt-confined nylon 6,6 fibres at the drawing temperature of $160^{\circ} \mathrm{C}$ at the band regions of (a) $4000-600 \mathrm{~cm}^{-1}$, (b) $1500-1100 \mathrm{~cm}^{-1}$ and (c) $1100-800 \mathrm{~cm}^{-1}$, Figure S4. XRD of the TMA $\mathrm{BF}_{4}$ salt, Figure S5. XRD pattern as-spun and drawn neat nylon 6,6 fibres, drawn at maximum draw ratio and at drawing temperature of 120,140 and $160{ }^{\circ} \mathrm{C}$, Figure S6. XRD pattern of $3 \%$ salt-confined as-spun and drawn nylon 6,6 fibres at drawing temperature of (a) 120, (b) 140 and (c) $160{ }^{\circ} \mathrm{C}$, Figure S7. The ACS of the salt-confined nylon 6,6 fibres for the (100) and the (010/110) diffraction planes versus the drawing ratio at different drawing temperatures, Figure S8. The tensile moduli, tensile strengths and elongation of the neat and the salt-confined nylon 6,6 fibres versus the drawing ratio at drawing 
temperatures of 120,140 and $160^{\circ} \mathrm{C}$, Figure S9. The FTIR spectrum of the salt-confined (drawn at, maximum, 5.5 draw ratio and at drawing temperature of $120^{\circ} \mathrm{C}$ ) and reverted nylon 6,6 fibres at the band regions of (a) $4000-600 \mathrm{~cm}^{-1}$, (b) $1500-1100 \mathrm{~cm}^{-1}$ and (c) $1100-800 \mathrm{~cm}^{-1}$, Figure S10. The FTIR spectrum of the salt-confined (drawn at, maximum, 5.5 draw ratio and at drawing temperature of $160{ }^{\circ} \mathrm{C}$ ) and reverted nylon 6,6 fibres at the band regions of (a) $4000-600 \mathrm{~cm}^{-1}$, (b) $1500-1100 \mathrm{~cm}^{-1}$ and (c) $1100-800 \mathrm{~cm}^{-1}$, Figure S11. XRD pattern of salt-confined nylon 6,6 fibres that drawn at, maximum, 5.5 draw ratio and at drawing temperature of (a) 120 and (b) $160{ }^{\circ} \mathrm{C}$ and its reverted fibres, Figure S12. SEM micrographs of the reverted nylon 6,6 fibres. The morphological cross-section structures of (a) the regenerated and (b) the stabilized nylon 6,6 fibres (the regeneration have been done for the $3 \%$ salt-confined nylon 6,6 fibres drawn at drawing ratio of 5.5 and drawing temperature of $120^{\circ} \mathrm{C}$ ). The morphological surfaces structures of (c) the regenerated and (d) the stabilized nylon 6,6 fibres (the regeneration have been done for the 3\% salt-confined nylon 6,6 fibres drawn at drawing ratio of 5.5 and drawing temperature of $120^{\circ} \mathrm{C}$ ). The morphological surfaces structures of (e) the regenerated and (f) the stabilized nylon 6,6 fibres (the regeneration have been done for the $3 \%$ salt-confined nylon 6,6 fibres drawn at drawing ratio of 5.5 and drawing temperature of $140{ }^{\circ} \mathrm{C}$ ). The morphological surfaces structures of $(\mathrm{g})$ the regenerated and $(\mathrm{h})$ the stabilized nylon 6,6 fibres (the regeneration have been done for the $3 \%$ salt-confined nylon 6,6 fibres drawn at drawing ratio of 5.5 and drawing temperature of $160^{\circ} \mathrm{C}$ ), Table S1. Crystallographic properties of the as-spun and drawn neat nylon 6,6 fibres, Table S2. Crystal Structural Parameters of Salt-confined and Reverted Nylon 6,6 Fibres.

Author Contributions: Conceptualization, A.D. and M.Y.; methodology, A.D. and M.Y.; writingreview and editing, A.D.; supervision, M.Y.; project administration, M.Y.; funding acquisition, M.Y. All authors have read and agreed to the published version of the manuscript.

Funding: National Basic Research Program of China (973 Project)-Grant 2011CB606101.

Institutional Review Board Statement: Not applicable.

Informed Consent Statement: Not applicable.

Data Availability Statement: Not applicable.

Acknowledgments: The first author which to extend their acknowledgements to the Shanghai Government Scholarship Council (SGS). Also, the authors are grateful to Lei Chen, Baihua Liu, Zhifeng $\mathrm{Hu}$, and Shiwei $\mathrm{Mu}$ for their useful help.

Conflicts of Interest: The authors declare that there is no conflict of interest regarding the publication of this manuscript.

\section{References}

1. Keller, A. Routes to High Modulus by Ultra-Orientation of Flexible Molecules. In Ultra-High Modulus Polymers; Ciferri, A., Ward, I.M., Eds.; Applied Science Publishers: London, UK, 1979; p. 321.

2. Yao, J.; Bastiaansen, C.W.M.; Peijs, T. High Strength and High Modulus Electrospun Nanofibers. Fibers 2014, 2, 158-186. [CrossRef]

3. Ward, I.M. Structure and Properties of Oriented Polymers; Holliday, L., Kelly, A., Eds.; Materials Science Series; Springer Science \& Business Media: Ripple Road, Barking, Essex, England, 1975.

4. Smith, P.; Lemstra, P.J. Ultra-drawing of high molecular weight polyethylene cast from solution. Colloid Polym. Sci. 1980, 258, 891-894. [CrossRef]

5. Smith, P.; Lemstra, P.J. Ultra-high-strength polyethylene filaments by solution spinning/drawing. J. Mater. Sci. 1980, 15, 505-514. [CrossRef]

6. Mark, H.; Whitby, G.S. (Eds.) Collected Papers of Wallace Hume Carothers on High Polymeric Substances. In High Polymers; Interscience Publishers, Inc.: New York, NY, USA, 1940; Volume 1.

7. Carothers, W.H.; Hill, J.W. Studies of polymerization and ring formation. XV. Artificial fibers from synthetic linear condensation superpolymers. J. Am. Chem. Soc. 1932, 54, 1579-1587. [CrossRef]

8. Lotz, B. Original Crystal Structures of Even-Even Polyamides Made of Pleated and Rippled Sheets. Macromolecules 2021, 54, 551-564. [CrossRef]

9. Hsiao, B.S.; Kennedy, A.D.; Barton, R., Jr.; Harlow, R.; Ross, R.; Seifert, S.; Zachmann, H.G. In-Situ Structural Characterization During Fiber Melt Spinning Via Synchrotron X-ray Diffraction Measurement. ACS Polym. Prep. 1995, 36, $340-341$.

10. Starkweather, H.W., Jr.; Whitney, J.F.; Johnson, D.R. Crystalline order in nylon 66. J. Polym. Sci. Part A Gen. Pap. 1963, 1, 715-723. [CrossRef]

11. Ramesh, C.; Keller, A.; Eltink, S. Studies on the crystallization and melting of nylon-6,6: The dependence of the Brill transition on the crystallization temperature. Polymer 1994, 35, 2483-2487. [CrossRef] 
12. Vergelati, C.; Imberty, A.; Perez, S. Water-induced crystalline transition of polyamide 66: A combined x-ray and molecular modeling approach. Macromolecules 1993, 26, 4420-4425. [CrossRef]

13. Militky, J.; Venkataraman, M.; Mishra, R. The chemistry, manufacture, and tensile behavior of polyamide fibers. In Handbook of Properties of Textile and Technical Fibres, 2nd ed.; Bunsell, A.R., Ed.; Woodhead Publishing Limited: Cambridge, UK, 2018; pp. 367-419. [CrossRef]

14. Tatsuya, H.; Phillips, G.; Takigami, M. New Millennium Fibers; Woodhead Publishing Limited: Cambridge, UK, 2005.

15. Lotz, B. Brill Transition in Nylons: The Structural Scenario. Macromolecules 2021, 54, 565-583. [CrossRef]

16. Danford, M.D.; Spruiell, J.E.; White, J.L. Structure development in the melt spinning of nylon 66 fibers and comparison to nylon. J. Appl. Polym. Sci. 1978, 22, 3351-3361. [CrossRef]

17. Postema, A.; Smith, P.; English, A.D. Ultra-drawing of polyamide: The hydrogen bond barrier. Polym. Commun. 1990, $31,444$.

18. Wendoloski, J.J.; Gardner, K.H.; Hirschinger, J.; Miura, H.; English, A.D. Molecular Dynamics in Ordered Structures: Computer Simulation and Experimental Results for Nylon 66 Crystals. Science 1990, 247, 431-436. [CrossRef]

19. Ward, I.M.; Coated, P.D. Introduction in Solid Phase Processing of Polymers; Ward, I.M., Coated, P.D., Dumoulin, M.M., Eds.; Hanser Publisher: Munich, Germany, 2000.

20. Mukhopadhyay, S.K. The Structure and Properties of Typical Melt-spun Fibres. Text. Prog. 1988, 18, 1-77. [CrossRef]

21. Zieminski, K.F.; Spruiell, J.E. On-line studies and computer simulation of the melt spinning of nylon-66 filaments. J. Appl. Polym. Sci. 1988, 35, 2223-2245. [CrossRef]

22. Shimizu, J. The Fine Structure of Super High Speed Spun Fibers and its Structure Development. Sen'i Gakkaishi 1982, 38, P499-P507. [CrossRef]

23. Shimizu, J.; Okui, N.; Kikutani, T. Fine Structure and Ohyscal Properties of Fibers Melt-Spun at High Speeds from Various Polymers; Ziabicki, A., Kawai, H., Eds.; John Wiley \& Sons: New York, NY, USA, 1985; p. 429.

24. Hancock, T.A.; Spruiell, J.E.; White, J.L. Wet spinning of aliphatic and aromatic polyamides. J. Appl. Polym. Sci. 1977, 21, 1227-1247. [CrossRef]

25. Roberts, M.F.; Jenekhe, S.A. Site-specific reversible scission of hydrogen bonds in polymers: An investigation of polyamides and their Lewis acid-base complexes by infrared spectroscopy. Macromolecules 1991, 24, 3142-3146. [CrossRef]

26. Jenekhe, S.A. Complexation-Mediated Solubilization of Polymers. U.S. Patent 4,963,616, 16 October 1990.

27. Vasanthan, N.; Kotek, R.; Jung, D.W.; Shin, D.; Tonelli, A.E.; Salem, D.R. Lewis acid-base complexation of polyamide 66 to control hydrogen bonding, extensibility and crystallinity. Polymer 2004, 45, 4077-4085. [CrossRef]

28. Afshari, M.; Gupta, A.; Jung, D.; Kotek, R.; Tonelli, A.; Vasanthan, N. Properties of films and fibers obtained from Lewis acid-base complexed nylon 6,6. Polymer 2008, 49, 1297-1304. [CrossRef]

29. Kanamoto, T.; Zachariades, A.E.; Porter, R.S. The effect of anhydrous ammonia on the crystalline-state deformation of nylons 6 and 6,6. J. Polym. Sci. Polym. Phys. Ed. 1982, 20, 1485-1496. [CrossRef]

30. Salem, D.R. Draw-Induced Structure Development in Flexible-Chain Polymers. In Structure Formation in Polymeric Fibers; Hanser: Munich, Germany, 2000; pp. 118-184.

31. Murthy, N.S. Structure of iodide ions in iodinated nylon 6 and the evolution of hydrogen bonds between parallel chains in nylon 6. Macromolecules 1987, 20,309-316. [CrossRef]

32. Harings, J.A.W.; Deshmukh, Y.S.; Hansen, M.R.; Graf, R.; Rastogi, S. Processing of Polyamides in the Presence of Water via Hydrophobic Hydration and Ionic Interactions. Macromolecules 2012, 45, 5789-5797. [CrossRef]

33. Suzuki, A.; Murata, H.; Kunugi, T. Application of a high-tension annealing method to nylon 66 fibres. Polymer 1998, 39, 1351-1355. [CrossRef]

34. Dumbleton, J.H.; Buchanan, D.R. Annealing experiments on drawn nylon 66 fibers. J. Polym. Sci. Part A Polym. Phys. 1968, 6 , 1527-1533. [CrossRef]

35. Dumbleton, J.H.; Buchanan, D.R.; Bowles, B.B. Characterization of nylon 66 structure from x-ray diffraction. J. Appl. Polym. Sci. 1968, 12, 2067-2078. [CrossRef]

36. Buchanan, D.R.; Dumbleton, J.H. Effect of annealing conditions on the structure of drawn nylon 66 yarns. J. Polym. Sci. Part A Polym. Phys. 1969, 7, 113-122. [CrossRef]

37. Suzuki, A.; Chen, Y.; Kunugi, T. Application of a continuous zone-drawing method to nylon 66 fibres. Polymer 1998, 39, 5335-5341. [CrossRef]

38. Zhang, Q.-X.; Yu, Z.-Z.; Yang, M.; Ma, J.; Mai, Y.-W. Multiple melting and crystallization of nylon-66/montmorillonite nanocomposites. J. Polym. Sci. Part B Polym. Phys. 2003, 41, 2861-2869. [CrossRef]

39. Lin, B.; Thümen, A.; Heim, H.P.; Scheel, G.; Sundararaj, U. Nylon 66/clay nanocomposite structure development in a twin screw extruder. Polym. Eng. Sci. 2009, 49, 824-834. [CrossRef]

40. Mert, M.; Yilmazer, U. Processing and properties of modified polyamide 66-organoclay nanocomposites. J. Appl. Polym. Sci. 2008, 108, 3890-3900. [CrossRef]

41. Li, L.; Li, C.Y.; Ni, C.; Rong, L.; Hsiao, B. Structure and crystallization behavior of Nylon 66/multi-walled carbon nanotube nanocomposites at low carbon nanotube contents. Polymer 2007, 48, 3452-3460. [CrossRef]

42. Meng, Q.-J.; Wang, Z.-M.; Zhang, X.-X.; Wang, X.-C.; Bai, S.-H. Fabrication and Properties of Polyamide-6,6-functionalized Carboxylic Multi-walled Carbon Nanotube Composite Fibers. High Perform. Polym. 2010, 22, 848-862. [CrossRef] 
43. Choi, E.-Y.; Kim, K.; Kim, C.-K.; Kang, E. Reinforcement of nylon 6,6/nylon 6,6 grafted nanodiamond composites by in situ reactive extrusion. Sci. Rep. 2016, 6, 37010. [CrossRef] [PubMed]

44. Wu, Y.; Xu, Y.; Wang, D.; Zhao, Y.; Weng, S.; Xu, D.; Wu, J. FT-IR spectroscopic investigation on the interaction between nylon 66 and lithium salts. J. Appl. Polym. Sci. 2004, 91, 2869-2875. [CrossRef]

45. Karacan, I.; Tunçel, K. Şahin Thermal stabilization of poly(hexamethylene adipamide) fibers in the presence of ferric chloride prior to carbonization. Polym. Degrad. Stab. 2013, 98, 1869-1881. [CrossRef]

46. Prasad, M.; Krishnan, K.; Ninan, K.; Krishnamurthy, V. Thermal decomposition of tetraalkyl ammonium tetrafluoroborates. Thermochim. Acta 1997, 297, 207-210. [CrossRef]

47. Ue, M. Mobility and Ionic Association of Lithium and Quaternary Ammonium Salts in Propylene Carbonate and $\gamma$-Butyrolactone. J. Electrochem. Soc. 1994, 141, 3336-3342. [CrossRef]

48. Park, S.; Kim, K. Tetramethylammonium tetrafluoroborate: The smallest quaternary ammonium tetrafluoroborate salt for use in electrochemical double layer capacitors. J. Power Sources 2017, 338, 129-135. [CrossRef]

49. Torre, S.; Ferloni, P. Molecular Motion in Solid Tetramethylammonium Tetrafluoroborate. Z. Nat. A 1992, 47, 721-727. [CrossRef]

50. Kumiko Sonoda, A.U.; Iwamoto, K. Non-Aqueous Electrolyte and Electrochemical Device Comprising the Same. U.S. Patent US20020028389A1, 7 March 2002.

51. Zabinska, G.; Ferloni, P.; Sanesi, M. On the thermal behaviour of some tetraalkylammonium tetrafluoroborates. Thermochim. Acta 1987, 122, 87-94. [CrossRef]

52. Delmerico, S.; McDaniel, J.G. Free energy barriers for TMEA+, TMA+, and BF4- ion diffusion through nanoporous carbon electrodes. Carbon 2020, 161, 550-561. [CrossRef]

53. Shivanyuk, A. Nanoencapsulation of Calix[4]arene Inclusion Complexes. J. Am. Chem. Soc. 2007, 129, 14196-14199. [CrossRef]

54. Kvasnica, M.; Purse, B.W. Specific tetramethylammonium recognition drives general anion positioning in tandem sites of a deep cavitand. New J. Chem. 2010, 34, 1097-1099. [CrossRef]

55. Smith, J.A.; Jaffe, P.R.; Chiou, C.T. Effect of ten quaternary ammonium cations on tetrachloromethane sorption to clay from water. Environ. Sci. Technol. 1990, 24, 1167-1172. [CrossRef]

56. Colclough, M.L.; Baker, R. Polymorphism in nylon. J. Mater. Sci. 1978, 13, 2531-2540. [CrossRef]

57. Galimberti, D.; Quarti, C.; Milani, A.; Brambilla, L.; Civalleri, B.; Castiglioni, C. IR spectroscopy of crystalline polymers from ab initio calculations: Nylon 6,6. Vib. Spectrosc. 2013, 66, 83-92. [CrossRef]

58. Vasanthan, N.; Salem, D.R. Infrared spectroscopic characterization of oriented polyamide 66: Band assignment and crystallinity measurement. J. Polym. Sci. Part B Polym. Phys. 2000, 38, 516-524. [CrossRef]

59. Vasanthan, N.; Ruetsch, S.B.; Salem, D.R. Structure development of polyamide-66 fibers during drawing and their microstructure characterization. J. Polym. Sci. Part B Polym. Phys. 2002, 40, 1940-1948. [CrossRef]

60. Palacios, E.; Melero, J.J.; Burriel, R.; Ferloni, P. Structural, calorimetric, and Monte Carlo investigation of the order-disorder transition of BF4 in (CH 3)4NBF4. Phys. Rev. B 1996, 54, 9099-9108. [CrossRef]

61. Shodai, Y.; Kohara, S.; Ohishi, Y.; Inaba, M.; Tasaka, A. Anionic Species (FH)xF- in Room-Temperature Molten Fluorides (CH3)4NF.mHF. J. Phys. Chem. A 2004, 108, 1127-1132. [CrossRef]

62. Parravicini, G.; Marabelli, F.; Floris, F.M.; Pasquali, V.; Parravicini, J.; Ferloni, P. Thermal evolution of tetramethylammonium tetrafluoborate and perchlorate investigated through dielectric and IR spectroscopy. Mater. Chem. Phys. 2014, 147, 120-126. [CrossRef]

63. Koller, J.; Grdadolnik, J.; Hadzi, D. Tetramethylammonium as proton donor in hydrogen bonding: An ab initio and infrared study. J. Mol. Struct. Theochem. 1992, 259, 199-209. [CrossRef]

64. Cannon, C. The infra-red spectra and molecular configurations of polyamides. Spectrochim. Acta 1960, 16, 302-319. [CrossRef]

65. Kang, E.; Kim, M.; Oh, J.S.; Park, D.W.; Shim, S.E. Electrospun BMIMPF6/nylon 6,6 nanofiber chemiresistors as organic vapour sensors. Macromol. Res. 2012, 20, 372-378. [CrossRef]

66. Bunn, C.W.; Garner, E.V. The Crystal Structures of Two Polyamides ('Nylons'). Proc. R. Soc. Lond. Ser. A Math. Phys. Sci. 1947, 189, 39-68.

67. Holmes, D.R.; Bunn, C.W.; Smith, D.J. The crystal structure of polycaproamide: Nylon 6. J. Polym. Sci. 1955, 17, 159-177. [CrossRef]

68. Matsumoto, K.; Harinaga, U.; Tanaka, R.; Koyama, A.; Hagiwara, R.; Tsunashima, K. The structural classification of the highly disordered crystal phases of [Nn][BF4], [Nn][PF6], [Pn][BF4], and [Pn][PF6] salts (Nn+ = tetraalkylammonium and Pn $+=$ tetraalkylphosphonium). Phys. Chem. Chem. Phys. 2014, 16, 23616-23626. [CrossRef]

69. Hsiao, B.S.; Kennedy, A.D.; Leach, R.A.; Chu, B.; Harney, P. Studies of Structure and Morphology Development During the Heat-Draw Process of Nylon 66 Fiber by Synchrotron X-ray Diffraction and Scattering Techniques. J. Appl. Crystallogr. 1997, 30, 1084-1095. [CrossRef]

70. Ran, S.; Cruz, S.; Zong, X.; Fang, D.; Chu, B.; Hsiao, B.S.; Ross, R.; Chang, H.; Londono, D. Structure Development during the Heat-Draw Process of Nylon 66 Fiber by Synchrotron X-ray Diffraction. Adv. X-ray Anal. 2000, 43, 313-318.

71. Keller, A. Crystal configurations and their relevance to the crystalline texture and crystallization mechanism in polymers. Kolloid Z. Z. Polym. 1964, 197, 98-115. [CrossRef]

72. Choy, C.L.; Leung, W.P.; Ong, E.L.; Wang, Y. Mechanical anisotropy in rolled nylon. J. Polym. Sci. Part B Polym. Phys. 1988, 26, 1569-1584. [CrossRef]

73. Ziabicki, A. Fundamentals of Fibre Formation; A Wiley-Interscience Publication: New York, NY, USA, 1976. 